•综述・

\title{
植物开花时间的遗传调控通路研究进展
}

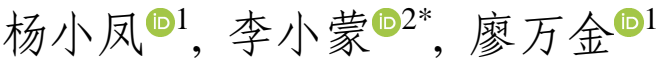

1. 北京师范大学生命科学学院, 生物多样性与生态工程教育部重点实验室, 北京 100875; 2. 北京师范大学, 生命科学与技术国家级实验教 学示范中心, 北京 100875

摘要：开花时间对植物的繁殖成功至关重要。广泛分布的物种经常发生开花时间的分化，从而能够更好地适应不同的环境条 件。为了探索植物开花行为发生适应性分化的分子机制, 首先要明确调控开花行为的遗传通路。本文梳理了植物各类群调控 开花时间的遗传通路，以期为开花时间适应性分化的分子机制研究提供依据。植物从营养生长向繁殖转变时，其开花行为主 要受到光照、温度、水分等外界环境因子和赤霉素等内在因素的影响。通过对模式植物拟南芥(Arabidopsis thaliana)和其他 类群的研究，总结出了调控植物开花时间的6条通路，包括日照长度和光质影响开花的光依赖通路，长时间冷暴露后促进植 物开花的春化通路, 高温或低温环境影响开花的温度通路, 以及赤霉素通路、年龄通路和自主通路3条内部调节过程。植物开 花时间调控的6条上游通路信号传递到下游的开花整合基因FT (FLOWERING LOCUS T) 和SOC1 (SUPPRESSOR OF OVEREXPRESSION OF CONSTANS 1), 整合基因将这些复杂的调节因子整合后进一步传递到下游花分生组织, 从而启动开花。此 外, 非编码RNA、转座子对开花时间的调控也具有重要作用。部分遗传通路被证实在植物适应环境的过程中起到了重要作用。 目前对植物开花调控的研究已经有一百多年历史, 理论相对成熟。然而, 仍然存在许多具有争议和未解决的问题, 如开花基 因的表达方式、开花行为的特殊调控机制、开花时间变异的适应性意义等等，需要更进一步的研究。

关键词: 开花基因; 开花时间; 适合度; 遗传调控; 遗传通路

杨小风, 李小蒙, 廖万金 (2021) 植物开花时间的遗传调控通路研究进展. 生物多样性, 29, 825-842. doi: 10.17520/biods.2020370. Yang XF, Li XM, Liao WJ (2021) Advances in the genetic regulating pathways of plant flowering time. Biodiversity Science, 29, 825-842. doi: 10.17520/biods.2020370.

\section{Advances in the genetic regulating pathways of plant flowering time}

\author{
Xiaofeng Yang ${ }^{(\mathbb{D} 1}$, Xiaomeng $\mathrm{Li}^{\text {(D)2* }}{ }^{\text {, Wanjin Liao }}{ }^{(\mathrm{D} 1}$
}

1 MOE Key Laboratory for Biodiversity Science and Ecological Engineering, College of Life Sciences, Beijing Normal University, Beijing 100875

2 National Demonstration Center for Experimental Life Sciences and Biotechnology Education, Beijing Normal University, Beijing 100875

\begin{abstract} ing time.

收稿日期: 2020-09-21; 接受日期: 2020-11-30

基金项目: 国家自然科学基金(31700326; 31770253)和中央高校基本科研业务费专项资金

* 通讯作者 Author for correspondence. E-mail: xiaomengli@bnu.edu.cn
\end{abstract}

Aims: Flowering time is critical for plant reproductive success. Plant species, especially which are widely distributed, are observed to exhibit significant differentiation in flowering time to maximize their fitness. In order to explore the molecular mechanism of adaptive differentiation of flowering time in plants, it is essential to clarify the regulating pathways of flowering. This paper summarizes the genetic pathways that regulate flowering time in various groups of plants, which can provide important reference for molecular mechanism research of adaptive differentiation of flower-

Progresses: As a vital transition from vegetative growth to reproduction in plants, the flowering time has been reported to be regulated by both extrinsic and intrinsic factors. Based on researches of the model plant Arabidopsis thaliana and other taxa, six pathways that regulate flowering time have been identified. The light-dependent pathway, vernalization pathway, and temperature pathway refer to the regulation of flowering time in response to day length or quality of light, a long period of cold exposure, and external high or low temperature, respectively. While the gibberellin pathway, the 
age pathway and the autonomic pathway are the endogenous pathways. Signals from the six upstream flowering regulation pathways are transmitted to the downstream flowering integrators FT (FLOWERING LOCUS T) and SOC1 (SUPPRESSOR OF OVEREXPRESSION OF CONSTANS 1), assembled by these two integrators, and transmitted to the downstream flowering meristem where flowering initiates. In addition, most recent studies have shown that non-coding RNA and transposable elements also play important roles in the regulation of flowering time.

Prospect: The researches on the regulation of plant flowering have studied more than a hundred years ago, forming many mature theories. However, there are still many controversial and unresolved problems, such as the expression ways of flowering genes, the special regulatory mechanism of flowering, and the adaptive significance of differentiated flowering time, which require further study.

Key words: flowering gene; flowering time; fitness; genetic regulation; genetic pathway

开花是决定植物繁殖成功的重要过程, 植物必 须准确地将内部信号和环境信号相结合然后启动 开花过程。最优的开花时间对于植物适合度收益的 最大化有着非常重要的影响, 在错误的时间开花可 能会使植物开花时间与传粉环境不匹配, 导致不能 够成功传粉, 从而产生更大的适合度代价(Kitamoto et al, 2006), 或者更易受到捕食者和致病菌的危害 (Elzinga et al, 2007; Lemoine et al, 2017)。开花过早 也可能会导致植物没有充足的营养来完成繁殖 (Elzinga et al, 2007)。有研究表明, 早开花导致入侵 北欧的普通豚草(Ambrosia artemisiifolia)种子产量 大幅度降低(Kralemann et al, 2018)。开花过晚可能 会使得植物错过资源利用的最佳时期而不能在生 长季结束之前完成繁殖过程, 也可能会因为相对于 周围早开花植物的竞争力减弱而使得后代处于不 利的环境中, 比如在植物高密度情况下对光照的竞 争不足(Vermeulen, 2015)。广泛分布的物种面临多 变的环境, 在适应不同环境的过程中, 很容易发生 生活史性状的适应性进化, 尤其是开花时间的适应 性进化(Barrett et al, 2008)。植物的开花时间受到自 然环境和遗传机制的共同作用, 在种间和种内呈现 出了丰富的多样性。研究者已开始探索开花时间多 样性产生的遗传基础, 尤其是开花时间的遗传通 路。

开花时间调控的研究已有 100 多年的历史 (Kobayashi \& Weigel, 2007), 涵盖了从基础的生理 研究到深入的遗传分子水平、从种间比较发展到种 间与种内相结合、从模式植物拟南芥(Arabidopsis thaliana)扩展到多种植物的研究。目前植物开花的 调控通路已经有了比较成型的框架(图1)。基于模式 植物拟南芥的研究发现, 开花时间受多种环境和内 源途径调控, 主要有6条调控通路, 包括光依赖、自 主、春化、赤霉素(gibberellin acid, GA)、温度以及 年龄通路(Fornara et al, 2010; Kinoshita \& Richter, 2020)。近些年对开花时间调控的研究主要围绕以上 6条通路开展。研究发现在花的诱导过程中, 有几个 基因在多个组织中起作用，它们将多个调节通路聚 集在一起，被称为整合基因(integrators)。这6条通路 汇集到整合基因，并由整合基因传递到下游的花分 生组织基因(floral meristem identity gene)中, 决定 花的形成。研究表明有上百个基因的突变会影响拟 南芥的开花时间(Srikanth \& Schmid, 2011)。有部分 基因被证明是导致自然种群开花时间变异的主要 原因, 主要涉及光受体基因、MADS转录因子基因、 FRI (FRIGIDA)和FRI-like 基因、昼夜节律基因、开 花素编码基因和RNA加工基因等(Alonso-Blanco et al, 2009; Rosloski et al, 2010; Weigel, 2012; Méndez-Vigo et al, 2013)。近几年来一些新的研究方 法应用于对开花时间遗传基础的研究当中, 并有了 许多新的发现。例如, microRNA对开花时间有重要 的影响, miR156和miR172调控年龄通路, miR159对 赤霉素通路有重要作用(Yamaguchi \& Abe, 2012)。 近年来发现转座子也对开花行为有一定的影响 (Tamaki et al, 2015)。有研究发现FLC (FLOWERING LOCUS C) 基因中转座子元件的插入会影响其表达, 从而影响开花时间(Tamaki et al, 2015; Niu et al, 2019)。除此之外, 碳水化合物如蔗糖、海藻糖等, 也 对开花行为有着显著影响(Bernler et al, 1993; Zhao et al, 2019)。综上所述, 调控开花时间的遗传通路错 综复杂, 对开花时间调控通路的归纳有助于更好地 厘清植物开花时间变化的分子机制及适应进化。

对植物开花时间调控的研究多集中于模式植 物拟南芥。但是拟南芥是一种长日照植物, 而光周 期对于开花具有很强的影响, 所以需要研究短日照 


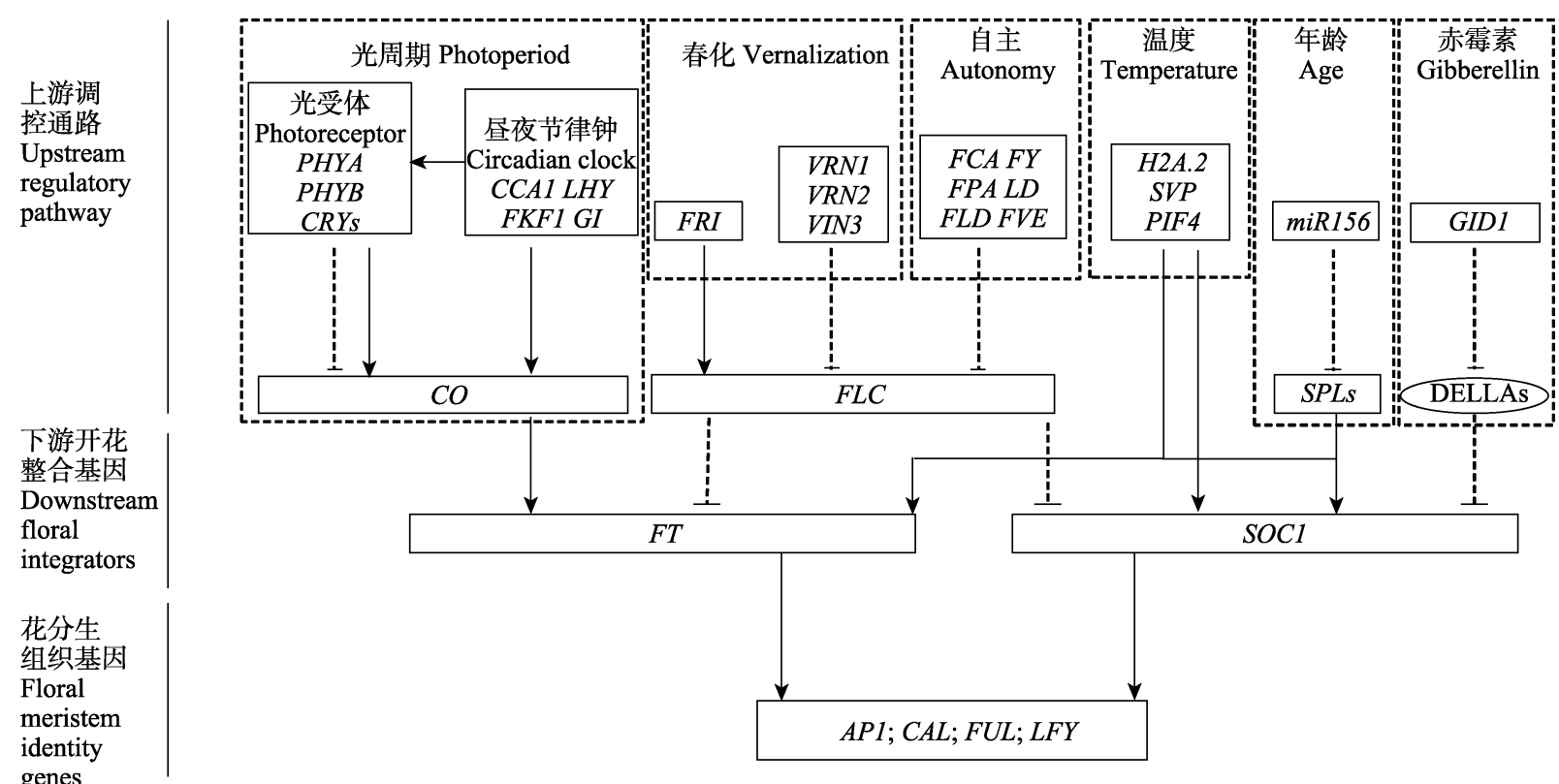

图1 调控开花行为的遗传通路(以拟南芥为例)。图中自上而下分为三部分：上游调控通路、下游开花整合基因和花分生组织 基因。虚线方框内代表拟南芥调控开花的 6 个通路以及相关的基因。方框内的大写字母代表基因的简称，椭圆框内的字母代 表蛋白的简称。带箭头的实线代表促进作用，平端的虚线代表抑制作用。改自Banta和Purugganan (2011)。

Fig. 1 The genetic pathways regulating flowering (take Arabidopsis thaliana as an example). The figure includes three parts from top to bottom: upstream regulatory pathway, downstream floral integrators and floral meristem identity genes. Six pathways and related genes that regulate flowering in Arabidopsis thaliana are enclosed in the dashed boxes separately. The letters in the boxes stand for abbreviation of genes, and the letters in the ovals stand for abbreviation of proteins. Lines with arrows indicate activation, and broken lines with blunt ends indicate repression. Modified from Banta \& Purugganan (2011).

植物和日中性植物开花的调控过程, 并分析开花调 控通路的保守性和差别性。目前对其他植物研究最 多的是水稻(Oryza sativa)、荠菜(Capsella rubella)、 踠豆(Pisum sativum)、烟草(Nicotiana tabacum)、番 茄(Solanum lycopersicum)等。经研究发现, 水稻作 为短日照植物的代表, 有许多与拟南芥功能相同的 开花相关基因。其他植物也具有许多与拟南芥同源 的开花基因，证明了从拟南芥中发现的开花通路具 有显著的保守性; 但是其他植物也有自己独特的开 花调控基因，说明了开花时间调控具有物种差异 性。本文将以拟南芥为代表综述主要的 6 个开花时 间调控通路和相应的开花时间调控基因, 并总结其 他植物在开花调控通路上的研究进展, 比较其在物 种间的保守性和差异性, 阐述此类研究中仍然存在 的争议和问题。

\section{1 开花调控上游通路}

\section{1 光依赖通路}

1.1.1 拟南芥中调控开花时间的光依赖通路基因 光是植物开花的主要环境调节因子之一。光周
期(昼夜长短)作为季节更替的重要信号, 能够诱导 植物进入繁殖期。光周期调控是开花时间调控的重 要机制。开花的光周期信号通路由三部分组成: 光 信号输入、节律钟(circadian clock)和信号输出(Shim et al, 2017)。高等陆生植物的光信号由红光/远红光 受体(光敏色素PHYA-E, PHYTOCHROME A-E)、蓝 光/UV-A受体(隐花色素CRY1-2, CRYPTOCHROME 1-2)、向光素PHOT1-2 (PHOTOTROPIN 1-2)、ZTL (ZEITLUPE)/FKF1 (FLAVIN-BINDING, KELCH REPEAT, F-BOX 1)/LKP2 (LOV KELCH PROTEIN 2)蛋白家族, 还有一种UV-B紫外光受体UVR8 (UV RESISTANCE LOCUS 8)感知(Mawphlang \& Kharshiing, 2017; Sanchez et al, 2020)。植物的节律钟系 统主要由复杂的信号网络形成，其核心组分通常具 有转录活性，通过具有时间特异性的多重反馈调控 (部分基因在特定的时间对另一部分基因产生调控, 形成周期性的调控回路)形成节律性振荡 (oscillator), 调节下游输出基因的表达，进而调控植 物各种生理反应的时机(Shim et al, 2017)。节律钟的 核心组分包括起抑制作用的转录因子 CCA 1 
(CIRCADIAN CLOCK ASSOCIATED 1)、LHY (LATE ELONGATED HYPOCOTYL)、 PRR9 (PSEUDORESPONSE REGULATORS 9)、PRR7、PRR5、ELF3 (EARLY FLOWERING 3)、ELF4、LUX (LUX ARRHYTHMO)和TOC1 (TIMING OF CAB EXPRESSION 1), 以及激活因子LWD1 (LIGHT- REGULATED WD 1)、LWD2和RVE8 (REVEILLE 8) (Shim et al, 2017)。 植物对光周期的感知需要光信号和节律钟系统共 同作用来完成。光信号通过光受体影响节律性振荡 的节律期(period)和相位(phase), 使得节律钟控制的 过程能够精确地与太阳活动周期相匹配(Yanovsky \& Kay, 2001)。同时，节律钟又通过调控某些光信号 组件(如GI (GIGANTEA), ELF3)来影响光对节律钟 的调控, 最终形成一定的昼夜节律, 直接或间接影 响下游基因的表达，使植物能够适应环境的周期性 变化(Yanovsky \& Kay, 2001)。

CO (CONSTANS) 是光周期路径的关键下游基 因。在长日照下 $C O$ 的表达被三种蛋白的活性修饰: GI、FKF1、CDF1 (CYCLING DOF FACTOR 1) (Imaizumi et al, 2005; Sawa et al, 2007; Fornara et al, 2009)。这三个基因本身受昼夜节律钟的调控。CDFs 属于转录调节因子家族, 通过直接与 $C O$ 调节区域 结合作为 $C O$ 转录的抑制因子(Fornara et al, 2009)。 在昼夜节律钟的调控下, CDFs、GI和FKF1先后表达, $F K F 1$ 与抑制 $C O$ 转录的 CDF1-GI复合物相互作用, 并通过其F-Box结构域使 CDF1降解(Sawa et al, 2007), 一旦CDF被降解, FBHs (FLOWERING BHLHs)和TCPs (TEOSINTE BRANCHED/CYCLOID EA/PROLIFERATING CELL NUCLEAR ANTIGEN FACTORs)将诱导 $C O$ 的转录(Ito et al, 2012; Kubota et al, 2017)。CO不仅在转录水平上受到调控, 其蛋 白质稳定性和积累水平也受到调控(图2A)。晚上, COP1-SPA1 (CONSTITUTIVE PHOTOMORPHOGE NIC 1-SUPPRESSOR OF PHYA 1)复合物降解CO蛋 白，以抑制在短日照下的开花(Jang et al, 2008)。而 存在蓝光时, 蓝光受体 $C R Y 2$ 与 $C O P 1-S P A 1$ 复合物 结合能够抑制对 $C O$ 蛋白的降解作用 (Zuo et al, 2011)。除此之外, 还有依赖ZTL/FKF1的调节机制, 早上, ZTL可能与 $G I$ 一起降低CO的稳定性(Song et al, 2014); 下午, FKF1通过抑制功能性COP1的同源 二聚化来增加CO蛋白(Lee et al, 2017)。由于 $G I$ 也与 $C O$ 直接相互作用, FKF1、GI和CO可能形成三聚体
复合物并稳定 $C O$ (Song et al, 2014)。除了与光周期 相关的调节外, $C O$ 蛋白的积累还受到光受体的影 响。红光受体 $P H Y B$ 在早上与 HOS1 (HIGH EXPRESSION OF OSMOTICALLY RESPONSIVE GENES 1)形成复合物抑制CO蛋白的积累(Lazaro et al, 2015); 远红光受体 PHYA促进CO蛋白的积累 (Valverde et al, 2004); $C R Y 2$ 感知蓝光并稳定 $C O$ (Zuo et al, 2011)。最终使得长日照下 $C O$ 在黎明和下 午表达, 进而使得 $F T$ 转录水平上调并诱导开花; 而 短日照下, 高水平的 $C O$ 表达在黑暗中发生, 不会上 调FT, 从而导致开花延迟(Putterill et al, 2004)。CO 还能诱导与 FT转运相关的 NaKR1 (SODIUM POTASSIUM ROOT DEFECTIVE 1)的表达, 从而促进 $F T$ 向茎尖分生组织转运, 最终诱导花芽的形成 (Shim et al, 2017)。在光周期通路中, 除了通过CO 途径影响下游基因外，GI也能通过miR172间接激活 $F T$ ，或通过与 $F T$ 启动子结合并与 $F T$ 抑制因子形成 复合物来直接激活FT, 从而促进开花(Sawa \& Kay, 2011)。最近有研究鉴定到两种新的FT转录增强子 Block E和Block $C$, 它们能够影响 $F T$ 表达对光周期 的响应(Zicola et al, 2019)。

\subsection{2 光依赖通路在其他植物中的保守性和差异性}

在其他植物中也鉴定到了光依赖途径相关基 因。例如在水稻中发现了许多拟南芥开花相关基因 的同源基因，如Hd1 (HEADING DATE 1)是CO的同 源基因(Yano et al, 2000), Hd3a和RFT1 (RICE FLOWERING LOCUS T 1)是FT的同源基因(Kojima et al, 2002), Hd6 是编码拟南芥CK2 (CASEIN KI$N A S E$ 2, 调节拟南芥生物钟活动和开花时间的物质) 的同源基因(Sugano et al, 1999), 表明了开花光依赖 通路的保守性。然而由于水稻是短日照植物, 调控 机制可能有所不同。如长日照下, 水稻中OsGI的过 度表达会促进 $H d 1$ 的表达，随后 $H d 1$ 抑制 $H d 3 a$ 的表 达，从而导致开花延迟; 而在拟南芥中 $G I$ 的过度表 达会促进 $C O$ 表达，进而促进FT的表达，使得开花 提前。在短日照下, 水稻中 $H d 1$ 促进 $H d 3 a$ 的表达从 而促进开花，而拟南芥CO则不会影响开花(Putterill et al, 2004)。此外，水稻中存在特有的调控途径: 在 短日照和长日照条件下, Ehd1 (EARLY HEADING DATE 1, CO 的同源基因)上调Hd3a和RFT1的表达促 进开花(Doi et al, 2004); Ghd7 (GRAIN NUMBER, 


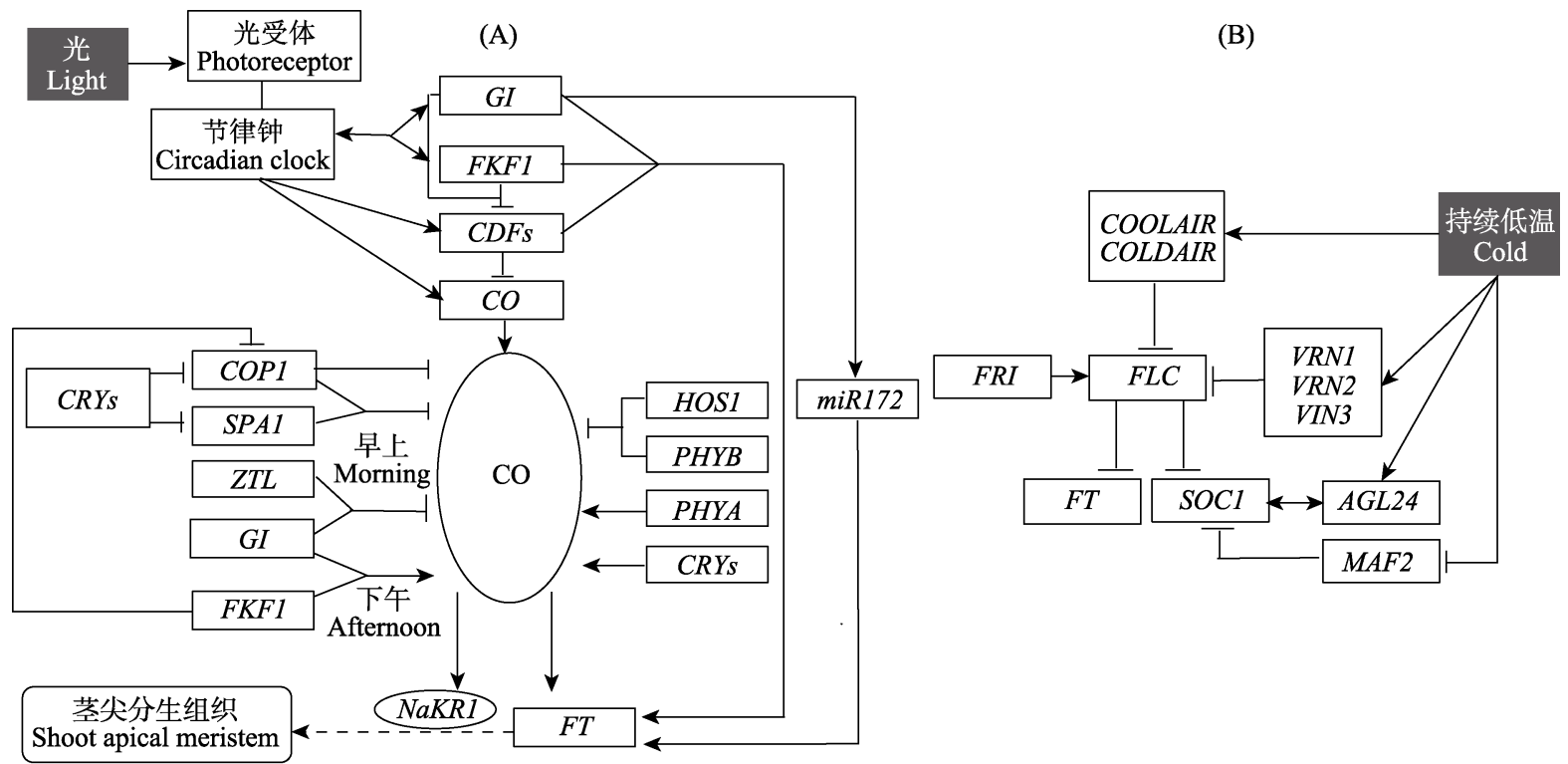

(C)

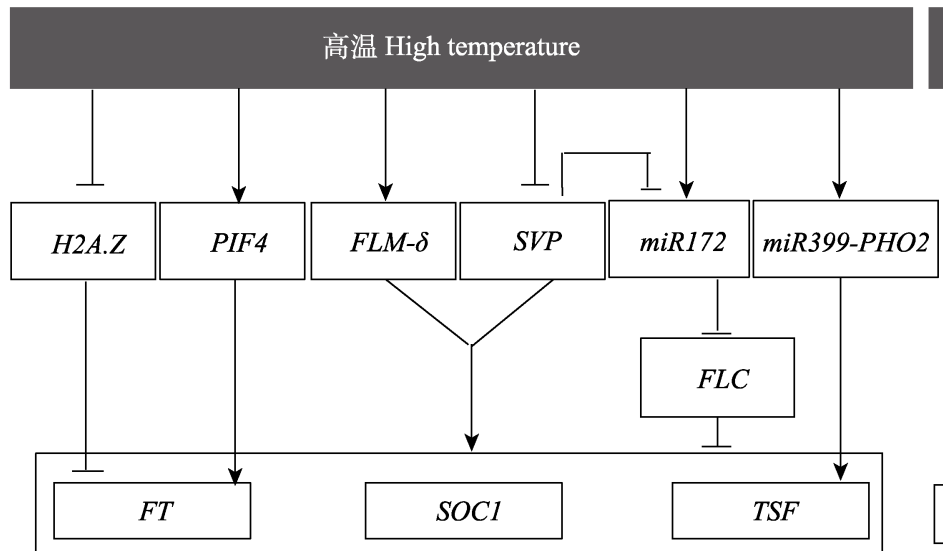

(D)

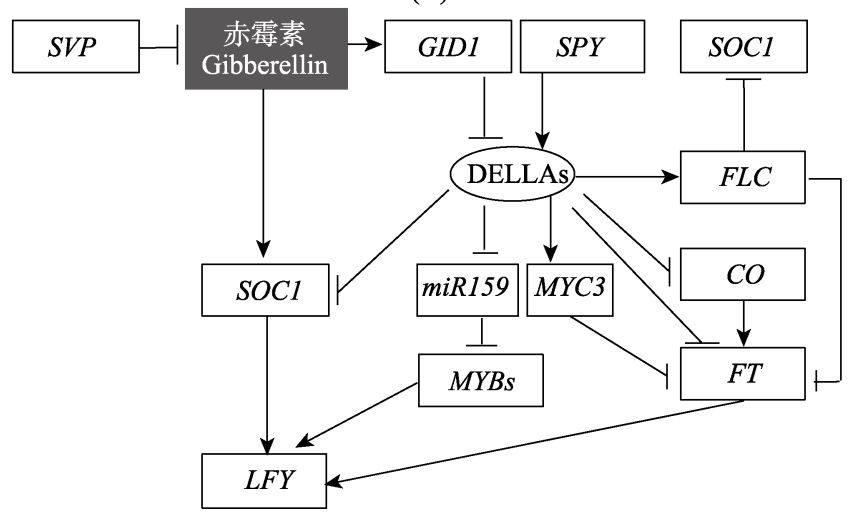

低温 Low temperature

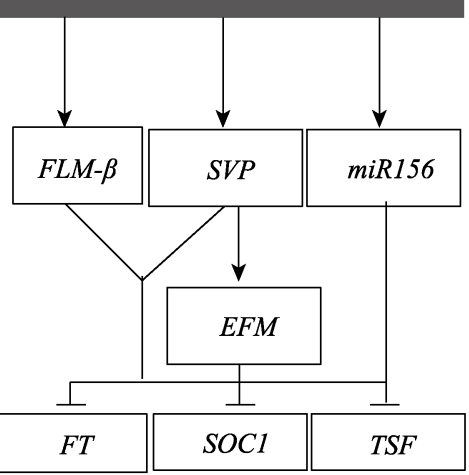

(E)

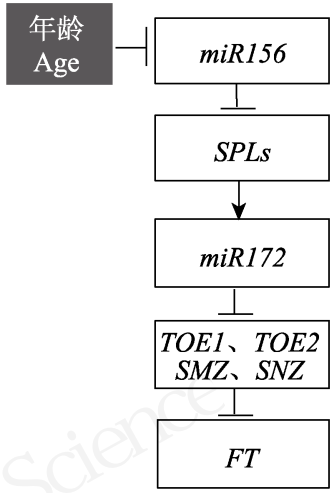

图2 拟南芥开花调控各通路的详细图解。(A)光周期通路; (B)春化通路; (C)温度通路; (D)赤霉素通路; (E)年龄通路。黑色填 充方框代表外界调节因子。方框内的字母代表基因的简称, 椭圆框内的字母代表蛋白的简称。带箭头实线代表促进作用, 平 端实线代表抑制作用。双向箭头代表相互作用。在图(A)中, 圆角矩形框指开花素转运到的位置, 带箭头的虚线代表转运过程。 Fig. 2 Detailed diagrams of the regulation pathways of flowering in Arabidopsis thaliana. (A) The photoperiodic pathway; (B) The vernalization pathway; (C) The temperature pathway; (D) The gibberellin pathway; (E) The age pathway. The black-filled box represents external regulating factors. The letters in the boxes stand for abbreviation of genes, and the letters in the ovals stand for abbreviation of proteins. Lines with arrows and blunt ends indicate activation and repression, respectively. The two-way arrows represent interactions. In figure (A), rectangle with rounded corners indicates the position where the florigen to be transferred, and the broken lines with arrows represent the transport process. 
PLANT HEIGHT, AND HEADING DATE 7)的表达随 日照长度增加而增加，该基因可下调 $E h d 1$ 的表达 (Itoh et al, 2010); Ghd8通过下调Hd3a表达抑制水稻 在长日照条件下的开花, 而最近的一项研究提出 Ghd8与 Ghd7的启动子结合, 可以诱导 Ghd7的表达 (Wang P et al, 2019)。此外, 即使短日照植物之间, 光周期的调控机制也有所不同，例如在菊花 (Chrysanthemum seticuspe)中, 长日照条件下CsGI (GI在菊花的同源基因)的过度表达会促进 $A F T$ (ANTI-FLORIGENIC FT/TFL1 FAMILY PROTEIN, $A F T$ 与 $F T$ 作用相反, $A F T$ 是开花抑制因子)的表达, 进而抑制开花(Oda et al, 2020), 这与水稻的OsGI抑 制 $H d 3 a$ 的表达从而导致开花延迟不同。牵牛花 (Pharbitis nil)也是短日照植物, 白天向夜晚转变的 生物钟系统引起花的转变, FT 的表达促进开花, 但 是与拟南芥不同的是, 牵牛花的 $F T$ 表达与 $C O$ 无关, 在牵牛花中可能存在着其他的节律调控响应光周 期(Hayama et al, 2007, 2018)。芒果(Mangifera indica)、番荔枝(Annona squamosa)中也发现了与开花 时间有关的GI、ELF3、CRY的同源基因(Liu KD et al, 2016; Yadav et al, 2020)。在甘野菊(Chrysanthemum eticuspe) 中鉴定到了拟南芥的大多数光依赖途径相 关基因, 如光受体、昼夜节律基因等, 但是与拟南 芥和水稻相比, 甘野菊的光依赖开花途径取决于绝 对黑暗持续时间, 并且对午夜的光照敏感 (Hirakawa et al, 2019)。台湾枇杷(Eriobotrya deflexa f. koshunensis)中基因 $E d G I$ 和 $E d C O$ 可能起着与拟南芥 中 $G I$ 和 $C O$ 相似的作用, 并调节枇杷的开花, 但是 $E d C O$ 的日变化规律与拟南芥不同, 枇杷可能已经 进化出不同的调控机制来控制 $E d C O$ 在不同光周期 条件下的昼夜表达(Zhang L et al, 2019)。这些研究 表明光依赖开花途径中的相关基因组成在不同的 物种中相对保守, 但每个基因的调控作用可能不同, 以此来应对不同的环境条件。

\subsection{3 光依赖途径与开花行为的多样性}

研究发现, 很多物种开花行为的变异与光依赖 途径相关基因的变异有关。在拟南芥、水稻、玉米 (Zea mays)、大麦 (Hordeum vulgare)等植物中发现了 多个能够解释开花光周期响应多样性的基因, 包括 光受体基因CRY2、PHYC、PHYD、CO及其同源基 因, 以及其他的一些调控基因, 如水稻中的 Ghd7、 玉米中的Vgt1 (VEGETATIVE TO GENERATIVE
TRANSITION 1)等(Alonso-Blanco et al, 2009)。此外, 近期研究又发现了一些导致开花时间多样性的光 依赖途径相关基因。例如大豆(Glycine max)中的 $P R R 3 b$ 和PRR37抑制开花，而E11 (a newly discovered QTL on chromosome 7)促进开花(Wang FF et al, 2019; Li et al, 2020; Wang LW et al, 2020)。小麦 (Triticum turgidum)中的PPD1 (PHOTOPERIOD 1) 和PRR1会影响开花时间(Shaw et al, 2020; Sun et al, 2020)。蔓菁 (Brassica rapa)中CCA1 基因的变异导致 了开花时间的分化(Yi et al, 2017)。水稻中的 SDG701 (SET DOMAIN GROUP 701)、ROC4 (RICE OUTERMOST CELL-SPECIFIC GENE 4)和Hd18对 开花有促进作用(Shibaya et al, 2016; Wei et al, 2016; Liu et al, 2017)。这些基因的变异最终使得植株在不 同的光周期条件下表现出不同的开花行为，并增强 植物在不同环境下的适合度。如大麦中 Ppd-H1 (PHOTOPERIOD-H1) 可促进在长日照下开花。中东 地区的大麦因携带这种基因而在春季迅速开花，以 应对漫长的白天和夏季干旱; 而北欧的大麦主要携 带突变的 $P p d-H 1$ 等位基因, 这些等位基因减少了其 对长日照的反应，从而使该植物能够在该地区较温 和的夏季生长, 并产生较高的种子产量(Turner et al, 2005)。

\section{2 春化通路}

Chourd在1960年将春化定义为“通过低温处理 获得或加速开花的能力”(Srikanth \& Schmid, 2011)。 一般来说，夏季一年生植物具有兼性春化反应，即 不进行低温处理也能够开花; 而冬季一年生植物具 有专性春化要求，即需要经过一段长时间的冷处理 才能够开花。基因FLC与FRI一直是春化通路研究的 重点，两者都是开花的抑制因子。FLC抑制下游开 花整合基因FT和SOC1的表达, 从而抑制开花。FRI 基因能上调FLC的表达，它的缺失会使FLC表达降 低以促进开花(Michaels \& Amasino, 2001)。FRI编码 一种含有卷曲螺旋域的蛋白(Johanson et al, 2000), 它与其他转录因子结合形成超级蛋白复合体, FRI 超级复合体通过在FLC的 $5^{\prime}$ 端形成一个具有活跃染 色质修饰和拓扑结构的局部染色体环境，进而促进 $F L C$ 的形成(Li et al, 2018)。

春化作用能够降低FLC mRNA水平以促进开 花(Sheldon et al, 2000)。在温度升高后, FLC mRNA 依然保持低水平, 但减数分裂后FLC mRNA重新分 
配回到正常值(Simpson \& Dean, 2002), 因此这种春 化状态不能由亲本传给子代。FLC的转录激活因子 对于在春化植物胚胎中重新激活FLC的表达很重要, 确保幼苗不受亲本春化作用的影响 (Yun et al, 2011)。在拟南芥中鉴定出了 3 个FLC 的调节因子: VRN1 (VERNALISATION 1)、VRN2 以及 VIN3 (VERNALISATION INSENSITIVE 3), 它们都是FLC 的负调节因子。有研究表明FLC在响应春化时是表 观沉默的。在寒冷时, VRN1和VRN2维持FLC的沉默 (Gendall et al, 2001); 而VIN3抑制FLC的表达, VIN3 在寒冷时能够被瞬间诱导产生(Sung \& Amasino, 2004)。另外还发现非编码RNA是一类新的基因表 达调控因子, 也能够调节FLC。例如在拟南芥中的 COOLAIR (COLD INDUCED LONG ANTISENSE INTRAGENIC RNA)和COLDAIR (COLD ASSISTED INTRONIC NONCODING RNA): 在寒冷条件下, COOLAIR 在VIN3发挥作用之前先转录, 抑制FLC的 转录(Swiezewski et al, 2009); COLDAIR在FLC被抑 制时激活，进一步抑制FLC (Heo \& Sung, 2011)。有 研究发现, 许多与FLC相关的转录因子如 MAF1-5 (MADS AFFECTING FLOWERING 1-5)和AGL24 (AGAMOUS-LIKE 24) 在春化反应中受到的调控独 立于FLC, 这些基因可能在调节春化反应中起着重 要的作用(Alexandre \& Hennig, 2008) (图2B)。如在 青菜(Brassica rapa var. chinensis)中, BcMAF2能够 直接与BCTEM1 (青菜的TEMPRANILLO 1 同源基因) 结合并促进其表达，从而抑制开花(Huang et al, 2019)。拟南芥在春化作用下, AGL24和SOC1能够上 调彼此的表达, 以独立于FLC的方式介导春化促进 开花(Michaels et al, 2003)。

除了十字花科植物以外, 很多植物中都发现了 $F L C$ 的同源基因, 包括双子叶植物和单子叶植物 (Reeves et al, 2007; Ruelens et al, 2013)。然而, 在3 种豆科植物(Lotus corniculatus var. japonicus, Medicago truncatula和Glycine max)中并未发现FLC的 同源基因 (Kim et al, 2013)。在藜属植物 Chenopodium quinoa Willd.中存在几个春化相关基 因，但并未鉴定到FLC的同源基因 (Golicz et al, 2020)。小麦、大麦等单子叶温带谷物由 3 个位点 (VRN1-3，与拟南芥的FLC的调节因子不相关只是 名字相同)决定春季和冬季习性; 基因 VRN1、VRN3 分别与拟南芥AP1 (APETALA 1) 和FT同源, 而VRN2
在拟南芥中没有同源基因，但在春化过程中起着类 似FLC的作用(Yan et al, 2003, 2004, 2006)。在这些 温带谷物中，VRN3 被VRN2抑制，寒冷暴露期间 $V R N 2$ 水平降低, VRN1水平升高, 从而促进 $V R N 3$ 的 表达和分生组织的转变(Sasani et al, 2009)。

拟南芥的春化需求是由FRI的显性活性赋予的 (Shindo et al, 2005), 而对荠菜的研究表明FLC是主 要的调控因素(Yang et al, 2018)。在甜菜(Beta vulgaris) 中, 有 3 个基因 BvBTC1 (BOLTING TIME $C O N T R O L$ 1)、BvFT1和BvFT2在春化中起作用, 其 中 $B v F T 1$ 和 $B v F T 2$ 与 $F T$ 最相关, $B v B T C 1$ 的显性等位 基因产生一年生品种，而隐性等位基因产生需要春 化的两年生品种(Pin et al, 2010, 2012)。这与拟南芥 相反。在拟南芥中, FRI的缺失使春化途径的需求最 小化，因而产生一年生的品系(Johanson et al, 2000)。因此, 比起保守性强的光周期通路, 春化通 路的差异性更强，反映了植物对不同环境条件的适 应。

\section{3 温度通路}

除了春化作用外, 外界环境温度还直接影响开 花行为。一般来说, 高环境温度促进开花, 而低环 境温度延迟开花(Jagadish et al, 2016)。拟南芥在较 高的环境温度下开花较早, 且在拟南芥的其他生活 型中, 较高的温度可以作为诱导性长日照的替代, 比如 $P H Y B$ 突变体在 $23^{\circ} \mathrm{C}$ 比在 $16^{\circ} \mathrm{C}$ 时开花早 (Halliday et al, 2003)。对拟南芥的研究发现, 不同温 度下FLM (FLOWERING LOCUS M) 的可变剪切体 和SVP (SHORT VEGETATIVE PHASE) 的稳定性影 响了开花行为, 同时发现 H2A.Z、PIF4 (PHYTOCHROME INTERACTING FACTOR 4)、 miR399-

PHO2 (microRNA399-PHOSPHATE 2)和 miR172基 因介导了高温对开花行为的影响, 而 $m i R 156$ 则是低 温下抑制开花的负调节因子(Verhage et al, 2014) (图2C)。FLM属于FLC家族, 在不同的环境温度下具 有不同的可变剪切体(Balasubramanian et al, 2006)。 其两个主要剪切体形成的蛋白通过与 SVP相互作用 而发挥拮抗作用, 在低温下产生的剪切体FLM- $\beta$ 是 一种开花抑制因子, 而高温下产生的剪切体FLM- $\delta$ 是开花的激活因子(Posé et al, 2013)。SVP蛋白在高 温下不稳定。在较低温度下, 相对增加的 $S V P$ 蛋白 与F $L M-\beta$ 相互作用，通过直接结合下游靶基因抑制 开花。长日照下的寒冷夜晚条件下 $F T$ 的表达会受到 
抑制, 导致开花延迟, 这主要是由于上述 $S V P-F L M-\beta$ 复合物的增加所导致的 (Kinmonth-Schultz et al, 2016)。FT、TSF (TWIN SISTER OF FT, FT的姊妹基因)和SOC1是开花行为 对环境温度响应过程中SVP、FLM和FLC基因的主 要下游靶点。SVP对FLC没有调节作用但它们可能 协同作用。两者在时间和空间上表现出相似的表达, 在 $F T$ 和 $S O C 1$ 上有共同的结合位点, 因此 $S V P$ 可能 以依赖FLC的方式调节这些基因的表达(Li et al, 2008)。MYB转录因子EFM (EARLY FLOWERING MYB PROTEIN)也介导环境温度对开花的影响, 直 接抑制叶片维管中 $F T$ 的表达。SVP和EFM主要在同 一调控途径中起着抑制开花的作用。EFM介导 $S V P$ 对温度响应通路下游的影响, 其表达受到 $S V P$ 的上 调从而抑制开花，并通过 H3K36me2 去甲基酶 $J M J 30$ 与光响应的昼夜节律钟相互作用(Yan et al, 2014)。在相对高温和短日照的环境下, 转录因子 PIF4结合并激活FT, 另外对 FT位点具有抑制性作 用的H2A.Z核小体的富集率降低，从而促进开花 (Kumar et al, 2012)。此外, 拟南芥在较高温 $\left(23^{\circ} \mathrm{C}\right)$ 和长日照条件下, $m i R 399 b$ 的过度表达和其靶基因 PHO2功能等位基因的缺失导致开花提前(Kim et al, 2011)。研究认为miR399-PHO2维持了磷稳态, 并通 过增加TSF的表达来调节开花时间 (Kim et al, 2011)。然而, 在miR399过量表达PHO2突变体植物 中磷酸盐毒性的间接后果也可能导致早开花, 需要 进一步研究(Spanudakis \& Jackson, 2014)。温度也能 够调节 $m i R 156$ 和 $m i R 172$ 的表达水平: 在较低温度 $\left(16^{\circ} \mathrm{C}\right)$ 下, miR156的表达受到促进导致开花延迟, 在较高的温度 $\left(23^{\circ} \mathrm{C}\right)$ 下, $m i R 156$ 表达受到抑制, 而 miR172则相反(Lee et al, 2010; Kim et al, 2012)。温 度对 miR172 的调控受到 SVP 的影响, SVP 抑制 $m i R 172$ 的表达, 而miR172则有可能通过抑制FLC来 促进开花(Lee et al, 2010)。此外, 有研究发现ICA (ICARUS) 编码转运RNA加工相关酶的基因, 其不 同的基因型能够改变拟南芥开花时间对温度的响 应行为(Méndez-Vigo et al, 2019)。

在中国水仙(Narcissus tazetta var. chinensis)中, 温度升高也促进了开花, 并且 $F T$ 同源基因 $N F T 1$ 在 高温下表达上调(Li et al, 2013)。郁金香(Tulipa gesneriana)和鹰香百合 (Lilium longiflorum)的开花 分别受高温和低温的诱导, 并且研究发现从鹿香百
合中鉴定到的LIFT基因以及从郁金香中分离出的 $T g F T 2$ 基因与从郁金香中分离出的 $T g F T 1$ 和 $T g F T 3$ 基因对开花时间的影响完全相反(Leeggangers et al, 2018)。另一方面, 有研究发现小麦和大麦在高温 $\left(25^{\circ} \mathrm{C}\right)$ 条件下, 在长日照下进行生殖发育, 而在短 日照下FT-like基因不表达，表明高温和日照时长条 件之间存在密切的相互作用, 并且研究发现 FPF1-like (FLOWERING PROMOTING FACTOR1-like)、RNase-S-like和VER2-like基因可能介导 了开花对高温的响应(Hemming et al, 2012)。对春兰 (Cymbidium goeringii)的研究发现, CgSVP基因作用 于 $C g A P 1$ 和 $C g S O C 1$, 在低温诱导开花行为的早期 可能起到了重要作用(Yang et al, 2019)。

总的来说, 对植物开花温度通路的研究相对较 少，主要集中在模式植物拟南芥中，且在拟南芥中 也存在许多未解决的问题，如 bHLH-PIFs (PIF3, PIF4，PIF5)和microRNAs等转录调节因子对开花基 因的差异调控。对其他植物的研究较少且发现的机 制也不完全一致。有的植物对于温度的反应可能与 拟南芥相反或者没有响应。在全球变暖的环境下, 植物如何响应变化的温度是值得关注的问题。

\section{4 自主通路}

除环境因素外, 植物的内部信号也参与调节开 花。自主通路相关基因的突变体FCA (FLOWERING LOCUS CA)、FY (FLOWERING LOCUS Y)、FPA (FLOWERING LOCUS PA)、LD (LUMINIDEPENDENS)、FLD (FLOWERING LOCUS D)、FLK (FLOWERING LOCUS KH DOMAIN)和FVE (FLOWERING LOCUS VE) 在长日照和短日照条件下开 花都较晚(Simpson, 2004; Srikanth \& Schmid, 2011), 但是这种晚开花的表型可以通过春化来恢复 (Abou-Elwafa et al, 2011)。近年来已经鉴定出了许 多新的自主通路相关基因。自主通路的关键调节因 子包括 FCA 、FPA、FVE、FLD、PCFS4 (PCF11P-SIMILAR PROTEIN 4)、PEP (PEPPER)、 FLK、HDA5 (HISTONE DEACETYLASE 5)、HDA6、 PRMT5 (PROTEIN ARGININE METHYLTRANSFE RASE 5)、PRMT10、DRM2 (DOMAINSREARRAN GEDMETHYLTRANSFERASE2)、CK2等(Cheng et al, 2017)。与春化通路的基因一样，自主通路的主要靶 基因也是FLC, 独立于光周期和温度通过抑制FLC 的表达来促进开花(Cheng et al, 2017)。自主通路基 
因主要通过调节FLC的mRNA形成过程、染色质表 观遗传修饰和对FLC翻译后调控来发挥作用(Cheng et al, 2017)。FCA、FPA、FVE以及 $F L D$ 共同作用, 调 节FLC的沉默(Liu et al, 2007; Bäurle \& Dean, 2008); PCFS4通过调控FCA的选择性加工, 促进开花(Xing et al, 2008); $P E P$ 与FLK功能拮抗, 通过转录和转录 后调控上调FLC (Ripoll et al, 2009); HDA5、FVE、 $F L D$ 和HDA6通过对FLC染色质中的H3K4去甲基化 和H3或H4去乙酰化抑制FLC表达(Luo et al, 2015); PRMT5和PRMT10通过不对称组蛋白精氨酸甲基微 调FLC的表达来控制开花, 并且两者的功能是独立 的(Niu et al, 2007); DRM2通过DNA甲基化参与了 表观遗传调控机制(Zhong et al, 2014); CK2通过磷 酸化和去磷酸化抑制FLC, 以翻译后的方式调节 FLC蛋白(Heidari et al, 2013; Mulekar \& Huq, 2015)。 最近有研究发现了两种富含甘氨酸的RNA结合蛋 白, 能同时与FCA、FPA和FLK作用, 并且还可以调 控FLM的可变剪切, 参与开花的自主和温度两个通 路(Steffen et al, 2019)。

在除了拟南芥以外的其他植物中也鉴定到了 自主通路的同源基因。例如在藜属植物 Chenopodium quinoa中鉴定到了拟南芥自主途径关 键基因FCA、FPA、FY、FVE、FLD、 $L D$ 的同源基 因, 但是缺失自主途径靶基因FLC (Golicz et al, 2020)。在生 丹(Paeonia suffruticosa)中鉴定到了FLD 的同源基因(Wang SL et al, 2019)。此外, 在甜菜中 鉴定到了 $F L K 、 F V E 、 L D$ 和 $L D L 1$ 基因。BVFLK与拟 南芥的 $F L K$ 基因功能相同, 但是 $B V F V E 1$ 的功能却 与拟南芥中的FVE不同, BVFVE1受昼夜节律钟的调 控(Abou-Elwafa et al, 2011), 说明自主通路具有一 定的保守性, 但不同植物中的作用机制存在一定差 异。

\section{5 赤霉素通路}

赤霉素是调节植物休眠、萌发、茎伸长和开花 等发育过程的植物激素。它不仅能刺激植物器官的 生长, 还能诱导发育阶段的转变(Mutasa-Göttgens \& Hedden, 2009)。赤霉素在某些植物(如拟南芥)中 促进开花, 而在其他植物(如苹果Malus $\times$ domestica) 中抑制开花, 因此赤霉素对于不同植物的作用具有 差异性(Zhang SW et al, 2019)。拟南芥中, 在短日照 条件下, 赤霉素促进开花作用最强(Porri et al, 2012)。在叶中, 赤霉素信号被GID1 (GA INSENSI-
TIVE DWARF 1)感知, GID1经历构象变化后使赤霉 素与DELLA (Asp-Glu-Leu-Leu-Ala)蛋白相互作用, 赤霉素启动 $D E L L A$ 蛋白的降解从而促进开花(Sun, 2010) (图2D)。SPY (SPINDLY)蛋白作为赤霉素信号 转导的抑制因子, 可能通过岩藻醣基化上调 DELLAs蛋白来延迟开花(Jacobsen et al, 1998; Zentella et al, 2017)。DELLA蛋白能直接与 $C O$ 结合从而 下调FT (Wang et al, 2016; Xu F et al, 2016), 还能够 与PIF4相互作用而抑制FT的表达(de Lucas et al, 2008)。除此之外, DELLA蛋白还能够与 $F T$ 的抑制因 子相互作用来抑制FT的表达, 如MYC3与 $D E L L A$ 蛋 白相互作用直接抑制FT (Bao et al, 2019)。另外, DELLA蛋白很可能与富集PRC2 (POLYCOM REPRESSIVE COMPLEX 2)的PKL (PICKLE)相互作用, $P R C 2$ 会提高FLC中的组蛋白标记 H3K27me3的水平, 使得FLC沉默, 从而调节FT和SOC1等靶基因, 进而 调控开花行为(Li et al, 2016; Campos-Rivero et al, 2017)。赤霉素还会通过抑制DELLA蛋白对 miR159 产生影响, 随后影响 $m i R 159$ 的靶序列MYB, 最终影 响LFY (LEAFY)的表达(Achard et al, 2004)。除了通 过DELLA蛋白的作用, 赤霉素还能够通过影响赤霉 素的生物合成和运输来调控开花, 主要与赤霉素氧 化酶有关, 它们能够将赤霉素前体转化为赤霉素活 性物质, 进而促进开花(Mitchum et al, 2006)。另一 方面, 赤霉素通过促进SOC1诱导基因(如AGL24)的 表达、下调植物开花抑制因子(如 $S V P$ ) 等多个途径来 调节SOC1的表达, 影响 LFY 的表达进而影响开花 (Li et al, 2008)。有研究发现SVP能够抑制赤霉素的 合成酶GA20ox2 (GIBBERELLIN 20 OXIDASE 2), 导致赤霉素含量降低, 从而抑制开花(Andrés et al, 2014)。

在其他物种中发现了拟南芥赤霉素途径相关 基因的同源基因，说明该途径具有一定的保守性。 在豚草的研究中发现, 中国北方的豚草(开花早)中 的SPY表达随着时间的推移而增加, 并且在开花后 高于南方的植物。因为 $S P Y$ 的表达可能阻断赤霉素 信号传导或赤霉素生物合成, 因此发育过程中 $S P Y$ 水平的增加可能与发育的转变有关(Li et al, 2015)。 在对芒果的研究中发现, 正常花芽与畸形花芽相比, $M Y B 、 A L G 24$ 以及赤霉素氧化相关基因的表达具有 显著差异, 说明花芽的发育与赤霉素途径密切相关 (Yadav et al, 2020)。在藜属植物Chenopodium quinoa 
中, 也鉴定到了许多 GID1和降解DELLA蛋白的同 源基因(Golicz et al, 2020)。Yano等(2015)的研究证 明在水稻中所有赤霉素调控途径都是由 GID1-DELLA系统调控的。

\section{6 年龄通路}

年龄通路为内源的开花调节通路, 主要由 mIR156-SPL (SQUAMOSA PROMOTER-BINDING PROTEIN-LIKE) 和 miR172-AP2 (APETALA 2) 调节 (Hyun et al, 2017)。miR156抑制SPL, 它能调节营养 阶段的生长, 受到糖有关的信号分子影响, 其表达 随着植物年龄的增长而减少, 使得SPLs 表达增加, 促进植物开花并向成熟期过渡(He et al, 2018)。在拟 南芥中, $S P L$ 基因可分为两大类, 其中 $m i R 156$ 识别 的有与开花相关的SPL2、SPL9、SPL10、SPL11、 $S P L 13$ 和SPL15, 以及促进花分生组织分化的SPL3、 SPL4和SPL5 (Hyun et al, 2016; Xu ML et al, 2016)。 $S P L 9$ 和SPL15结合 $m i R 172 b$ 基因的启动子促进其表 达, 再通过抑制开花抑制基因AP2-like的表达促进 开花, AP2-like基因TOE1 (TARGET OF EARLY ACTIVATION TAGGED 1)、TOE2、SNZ (SCHNARCHZAPFEN)、SMZ (SCHLAFMUTZE)都被证明是开 花抑制因子, 它们抑制FT的表达(Mathieu et al, 2009; Zhu \& Helliwell, 2011; Song et al, 2013) (图 2E)。

萝卜(Raphanus sativus)中也发现了与年龄途径 有关的基因, 如SPL1、SPL2、SPL3、SPL9、SPL13 和SPL15, 它们与抽苔和开花有关(Nie et al, 2016)。 而在藜属植物Chenopodium quinoa中鉴定到了SPL9 的同源基因, 它作为相对保守的 $m i R 156$ 的靶基因, 可能参与控制开花行为(Golicz et al, 2020)。对柳枝 稷(Panicum virgatum)的研究发现, SPL7和SPL8通过 直接上调SEP3 (SEPALLATA 3)和MADS32诱导开花, 而下调SPL7和SPL8会导致植株开花延迟或不开花, 这与拟南芥十分不同, 因此SPL7/8的调节代表了一 种禾本科的新的调控机制(Gou et al, 2019)。另外, $S P L 7 / 8$ 基因的下调能够逆转花序由生长向生殖的 转换, 在其他禾本科植物中没有发现这一现象(Gou et al, 2019)。

对开花调控年龄通路的研究还存在许多问题, 如在SPLs家族中还有许多成员的功能未知。SPLS在 禾本科植物开花中的作用仍不明确 (Gou et al, 2019)。此外, 年龄通路与糖的调节关系也需要进一
步研究。

\section{开花调控通路的下游基因}

\section{1 开花整合基因}

在拟南芥中6条开花通路汇集到开花整合基因 中, 开花整合基因接收上游的信号并通过激活参与 花形成过程的下游基因来促使开花行为的发生。其 中两个基因 FT和 SOC1 作为关键的开花转变基因启 动花的发育。

SOC1在分生组织中产生, 为开花的正调控因 子, 其表达能影响下游基因的表达并促进开花。 SOC1 将上游多条通路的信号整合, 传递到下游花 分生组织基因如 $L F Y 、 F U L$ (FRUITFULL)中, 以启 动花的发育。SOC1受 $C O$ 、赤霉素信号和 $m i R 156 / S P L$ 的正向调节(Moon et al, 2003; Fernández et al, 2016)。同时, SOC1是FLC的靶基因, FLC通过抑制 SOC1的表达抑制开花。另外, SOC1 与另一种 MADS-box蛋白AGL24的活性密切相关, 两者之间 相互影响, 而AGL24的表达受到光依赖途径、春化 通路和赤霉素途径的正向调节(Srikanth \& Schmid, 2011)。

在拟南芥中, $F T$ 的表达能够促进开花。 $F T$ 具有 多个转录调节因子, 其中 $C O$ 是 $F T$ 的正调节因子, 能够促进FT的表达以促进开花。 $R A V$ 家族的两个包 含 AP2域的转录因子(TEM1, TEM2)和euAP2基因家 族的6个基因(AP2, SMZ, SNZ, TOE1,TOE2,TOE3), 它们作为 $F T$ 的抑制因子抑制开花(Kim et al, 2006)。 除了这些类似AP2的转录因子外, FT还受到 SVP、 FLC的抑制(Srikanth \& Schmid, 2011)。对拟南芥的 研究发现, $F T$ 蛋白至少是开花素的一部分(Andrés \& Coupland, 2012), 开花素是由叶片产生的在茎尖诱 导花芽形成的可传递信号, 通过韧皮部从叶片移动 到顶端(Corbesier et al, 2007)。与SOC1在分生组织产 生并发挥作用不同的是, FT作为一种长距离信号诱 导开花(Corbesier et al, 2007), FT在叶片的韧皮部表 达, $F T$ 蛋白经韧皮部的伴胞运输到分生组织, 与 $F D$ (FLOWERING LOCUS D)相互作用形成FT-FD复合 物促进下游花分生组织基因 $A P 1$ 的表达, 从而启动 植株的开花, 随后FT-FD复合物含量下降(Abe et al, 2019)。

在对开花素的研究中, 不管是长日照植物还是 短日照植物或是日中性植物, 都鉴定到了FT的同源 
基因, 并且都为开花调控通路的整合基因, 且大多 数能够促进开花, 说明了FT功能的保守性(Shim \& Jang, 2020)。在与拟南芥同属芸苔属的其他物种如 蔓菁(Brassica rapa)和野甘蓝(B. oleracea)中, 只发 现了部分拟南芥开花基因, 这可能与芸苔属进化的 复杂性有关(Schiessl et al, 2017)。例如欧洲油菜 (Brassica napus)中鉴定到了FT的同源基因, 但大部 分基因发生了结构改变进而导致功能的改变 (Schiessl et al, 2017)。在短日照植物水稻中鉴定到了 其特有的基因 $R F T 1$, 当 $H d 3 a$ 的功能受到抑制时, $R F T 1$ 作为 $H d 3 a$ 的功能辅助基因, 能够确保植株开 花以繁衍后代(Komiya et al, 2008)。在对豚草的研究 中发现了两个 FT 的同源基因 AaFTL1 和 AaFTL2 (Kralemann et al, 2018)。两者具有不同的功能: $A a F T L 1$ 是开花激活因子, AaFTL2是开花抑制因子 (Kralemann et al, 2018)。除了被子植物, 在裸子植物 如华山松(Pinus armandii)、粗榧(Cephalotaxus sinensis)、银杏 (Ginkgo biloba)中, 也鉴定到了FT的同 源基因, 并且它们在生长和繁殖中起着与FT相似的 作用, 但是在有的植物如粗榧中FT-like基因起抑制 开花的作用(Liu YY et al, 2016)。

\section{2 花分生组织基因}

花分生组织基因的分子功能是DNA转录因子。 上游的花整合基因传递到下游的花分生组织基因, 花分生组织基因在茎尖分生组织中上调, 从而诱导 开花。如拟南芥中, FT和TSF基因从叶片传输到茎尖 分生组织, 它们与 $F D$ 形成一个复合物, 激活花分生 组织基因(包括 $A P 1$ 和 $F U L$ )的过表达(Perrella et al, 2020)。对拟南芥的突变体研究已经鉴定出 $L F Y$ 、 $A P 1 、 C A L$ (CAULIFLOWER)基因参与花原基的形成 (Busch et al, 1999)。LFY基因的组成性表达可加速开 花, 同时 $L F Y$ 还可以诱导 $A P 1$ 和 $C A L$ 的表达 (Liljegren et al, 1999)。花分生组织基因在植物之间 保守性强, 如在牡丹、豚草中鉴定到了花分生组织 基因 $C A L$ 和 $A P 1$ 诱导开花(Mátyás et al, 2019; Wang SL et al, 2019)。在茶 树(Camellia sinensis)中LFY的表 达也与花芽的形成相关(Liu et al, 2020)。

\section{3 展望}

开花行为的发生是环境条件和遗传调控共同 作用的结果, 因此在实验中, 特别是在受控条件下, 通过选择个体的环境条件, 如光周期、温度、光质
量、营养或其他实验变量, 可以观察到某一等位基 因功能缺失产生的表型, 从而揭示它们在开花时间 调控中的作用。目前对开花调控的研究已经有一百 多年的历史, 相比其他性状具有更成熟的理论, 但 是仍然存在许多具有争议和未解决的问题。

首先, 开花相关基因的表达部位和表达时间是 否具有一定的特异性? 为什么存在这种特异性? 例如, 研究发现 $F T$ 基因只在韧皮部伴胞表达 (Takada \& Goto, 2003)。那么表达FT的韧皮部伴胞 是否能相互传递信号使得 $F T$ 的表达在组织内和组 织间同步? FT在叶片中产生, 后作为开花信号被运 输到茎尖, $F T$ 是通过什么方式从叶片韧皮部到达茎 尖分生组织? 有研究认为 $F T$ 是通过胞问连丝运输 的，并且鉴定到有两种膜相关蛋白 FTIP1 (FT-Interacting Protein 1) 和NaKR1作为FT运动的分 子转运蛋白(Liu et al, 2012; Zhu et al, 2016)。但是对 于 $F T$ 蛋白的运动仍然存在很多疑问, 仍需要进一步 的研究。从表达时间看, 为什么拟南芥植物在早晨 具有多种 $C O$ 抑制机制? 这是否意味着植物可以在 早晨根据各种外部和内部条件来微调 $C O$ 的活性?

其次, 开花通路调控的分子机制有哪些? 除了 一些常见的基因、转录因子的调控外, 还有一些特 殊的调控机制, 如microRNA、转座子、可变剪切的 调控等等。目前已发现miR172、miR156等microRNA 在环境温度、赤霉素和年龄调节开花时间的途径中 起到了重要作用, 但具体机制还需要进一步研究 (Lee et al, 2010; Kim et al, 2012; Verhage et al, 2014)。已有研究发现转座子能够调控开花时间。如 拟南芥3'UTR中的转座子可以通过甲基化来改变基 因表达, 而水稻的转座子可以改变基因的翻译效 率。对荠菜的研究发现在FLC的 $3^{\prime} \mathrm{UTR}$ 处插入转座 子会影响FLC mRNA的稳定性, 降低FLC的表达水 平并导致开花提前(Niu et al, 2019)。转座子的功能 以及它在其他物种中的作用还不清楚, 有待进一步 研究。此外, 对mRNA的剪切是转录后调控的重要 步骤。虽然研究发现很少有剪切因子参与到开花转 变中, 但是仍然存在可变剪切参与开花调控的可能 (Wang P et al, 2020)。最近有研究发现, 椰子(Cocos nucifera) 有需要7-8年才能开花的高椰子和2-3年就 能开花的矮椰子两种生活型, 短的FT可变剪切体只 存在于矮椰子中, 证明了 FT的可变剪切可能与梆子 的开花时间的遗传调控有关(Xia et al, 2020)。但这 
种调控作用有待进一步研究。

开花时间的变异直接关系到植物对环境的适 应，因此了解不同物种开花时间变异的分子机制至 关重要。例如最近发现在水稻中 4 个关键的开花基 因(Hd1、OsPRR37、DTH8、Hd6)参与了温度对开 花时间的可塑性的调控, 使得水稻能够适应不同温 度条件, 这可能与开花基因发生遗传变异有关(Guo et al, 2020)。由于植物自身发育过程的不同阶段之 间相互影响(如萌发时间的差异会使植物处于不同 的环境中, 从而影响开花行为), 再加上基因具有多 效性机制(如开花相关基因也会影响种子的萌发情 况), 因此在研究开花时间调控机制时，还应考虑基 因通过环境产生的多效性间接作用。

\section{ORCID}

杨小凤 (10) https://orcid.org/0000-0001-6024-2229

李小蒙 (iD) https://orcid.org/0000-0002-7125-3588

廖万金 (iD) https://orcid.org/0000-0001-7928-9043

\section{参考文献}

Abe M, Kosaka S, Shibuta M, Nagata K, Uemura T, Nakano A, Kaya H (2019) Transient activity of the florigen complex during the floral transition in Arabidopsis thaliana. Development, 146, dev171504.

Abou-Elwafa SF, Büttner B, Chia T, Schulze-Buxloh G, Hohmann U, Mutasa-Göttgens E, Jung C, Müller AE (2011) Conservation and divergence of autonomous pathway genes in the flowering regulatory network of Beta vulgaris. Journal of Experimental Botany, 62, 3359-3374.

Achard P, Herr A, Baulcombe DC, Harberd NP (2004) Modulation of floral development by a gibberellin-regulated microRNA. Development, 131, 3357-3365.

Alexandre CM, Hennig L (2008) FLC or not FLC: The other side of vernalization. Journal of Experimental Botany, 59, 1127-1135.

Alonso-Blanco C, Aarts MGM, Bentsink L, Keurentjes JJB, Reymond M, Vreugdenhil D, Koornneef M (2009) What has natural variation taught us about plant development, physiology, and adaptation? The Plant Cell, 21, 1877-1896.

Andrés F, Coupland G (2012) The genetic basis of flowering responses to seasonal cues. Nature Reviews Genetics, 13, 627-639.

Andrés F, Porri A, Torti S, Mateos J, Romera-Branchat M, Garcia-Martinez JL, Fornara F, Gregis V, Kater MM, Coupland G (2014) SHORT VEGETATIVE PHASE reduces gibberellin biosynthesis at the Arabidopsis shoot apex to regulate the floral transition. Proceedings of the National Academy of Sciences, USA, 111, E2760-E2769.
Balasubramanian S, Sureshkumar S, Lempe J, Weigel D (2006) Potent induction of Arabidopsis thaliana flowering by elevated growth temperature. PLoS Genetics, 2, e106.

Banta, JA, and Purugganan MD (2011) The genetics and evolution of flowering time variation in plants: Identifying genes that control a key life history transition. In: Mechanisms of life history evolution (eds Flatt T, Heyland A), pp. 114-126. Oxford University Press Inc., New York.

Bao SJ, Hua CM, Huang GQ, Cheng P, Gong XM, Shen LS, Yu H (2019) Molecular basis of natural variation in photoperiodic flowering responses. Developmental Cell, 50, 90-101.

Barrett SCH, Colautti RI, Eckert CG (2008) Plant reproductive systems and evolution during biological invasion. Molecular Ecology, 17, 373-383.

Bäurle I, Dean C (2008) Differential interactions of the autonomous pathway RRM proteins and chromatin regulators in the silencing of Arabidopsis targets. PLoS ONE, 3, e2733.

Bernler G, Havelange A, Houssa C, Petitjean A, Lejeune P (1993) Physiological signals that induce flowering. The Plant Cell, 5, 1147-1155.

Busch MA, Bomblies K, Weigel D (1999) Activation of a floral homeotic gene in Arabidopsis. Science, 285, 585-587.

Campos-Rivero G, Osorio-Montalvo P, Sánchez-Borges R, Us-Camas R, Duarte-Aké F, De-La-Peña C (2017) Plant hormone signaling in flowering: An epigenetic point of view. Journal of Plant Physiology, 214, 16-27.

Cheng JZ, Zhou YP, Lv TX, Xie CP, Tian CE (2017) Research progress on the autonomous flowering time pathway in Arabidopsis. Physiology and Molecular Biology of Plants, 23, 477-485.

Corbesier L, Vincent C, Jang S, Fornara F, Fan QZ, Searle I, Giakountis A, Farrona S, Gissot L, Turnbull C, Coupland G (2007) FT protein movement contributes to long-distance signaling in floral induction of Arabidopsis. Science, 316, 1030-1033.

de Lucas M, Davière JM, Rodríguez-Falcón M, Pontin M, Iglesias-Pedraz JM, Lorrain S, Fankhauser C, Blázquez MA, Titarenko E, Prat S (2008) A molecular framework for light and gibberellin control of cell elongation. Nature, 451, 480-484.

Doi K, Izawa T, Fuse T, Yamanouchi U, Kubo T, Shimatani Z, Yano M, Yoshimura A (2004) Ehd1, a B-type response regulator in rice, confers short-day promotion of flowering and controls FT-like gene expression independently of $H d 1$. Genes \& Development, 18, 926-936.

Elzinga JA, Atlan A, Biere A, Gigord L, Weis AE, Bernasconi G (2007) Time after time: Flowering phenology and biotic interactions. Trends in Ecology \& Evolution, 22, 432-439.

Fernández V, Takahashi Y, Le Gourrierec J, Coupland G (2016) Photoperiodic and thermosensory pathways interact through CONSTANS to promote flowering at high temperature under short days. The Plant Journal, 86, 426-440. 
Fornara F, de Montaigu A, Coupland G (2010) SnapShot: Control of flowering in Arabidopsis. Cell, 141, 550-550.e2.

Fornara F, Panigrahi KCS, Gissot L, Sauerbrunn N, Rühl M, Jarillo JA, Coupland G (2009) Arabidopsis DOF transcription factors act redundantly to reduce CONSTANS expression and are essential for a photoperiodic flowering response. Developmental Cell, 17, 75-86.

Gendall AR, Levy YY, Wilson A, Dean C (2001) The VERNALIZATION 2 gene mediates the epigenetic regulation of vernalization in Arabidopsis. Cell, 107, 525-535.

Golicz AA, Steinfort U, Arya H, Singh MB, Bhalla PL (2020) Analysis of the quinoa genome reveals conservation and divergence of the flowering pathways. Functional \& Integrative Genomics, 20, 245-258.

Gou JQ, Tang CR, Chen NC, Wang H, Debnath S, Sun L, Flanagan A, Tang YH, Jiang QZ, Allen RD, Wang ZY (2019) SPL7 and SPL8 represent a novel flowering regulation mechanism in switchgrass. New Phytologist, 222, 1610-1623.

Guo TT, Mu Q, Wang JY, Vanous AE, Onogi A, Iwata H, Li XR, Yu JM (2020) Dynamic effects of interacting genes underlying rice flowering-time phenotypic plasticity and global adaptation. Genome Research, 30, 673-683.

Halliday KJ, Salter MG, Thingnaes E, Whitelam GC (2003) Phytochrome control of flowering is temperature sensitive and correlates with expression of the floral integrator FT. The Plant Journal, 33, 875-885.

Hayama R, Agashe B, Luley E, King R, Coupland G (2007) A circadian rhythm set by dusk determines the expression of FT homologs and the short-day photoperiodic flowering response in Pharbitis. The Plant Cell, 19, 2988-3000.

Hayama R, Mizoguchi T, Coupland G (2018) Differential effects of light-to-dark transitions on phase setting in circadian expression among clock-controlled genes in Pharbitis nil. Plant Signaling \& Behavior, 13, e1473686.

He J, Xu ML, Willmann MR, McCormick K, Hu TQ, Yang L, Starker CG, Voytas DF, Meyers BC, Poethig RS (2018) Threshold-dependent repression of SPL gene expression by miR156/miR157 controls vegetative phase change in Arabidopsis thaliana. PLoS Genetics, 14, e1007337.

Heidari B, Nemie-Feyissa D, Kangasjärvi S, Lillo C (2013) Antagonistic regulation of flowering time through distinct regulatory subunits of protein phosphatase 2A. PLoS ONE, 8, e67987.

Hemming MN, Walford SA, Fieg S, Dennis ES, Trevaskis B (2012) Identification of high-temperature-responsive genes in cereals. Plant Physiology, 158, 1439-1450.

Heo JB, Sung S (2011) Vernalization-mediated epigenetic silencing by a long intronic noncoding RNA. Science, 331, 76-79.

Hirakawa H, Sumitomo K, Hisamatsu T, Nagano S, Shirasawa K, Higuchi Y, Kusaba M, Koshioka M, Nakano Y, Yagi M, Yamaguchi H, Taniguchi K, Nakano M, Isobe SN (2019) De novo whole-genome assembly in Chrysanthemum seticuspe, a model species of Chrysanthemums, and its application to genetic and gene discovery analysis. DNA Research, 26, 195-203.

Huang FY, Liu TK, Tang J, Duan WK, Hou XL (2019) BcMAF2 activates BCTEM1 and represses flowering in Pak-choi (Brassica rapa ssp. chinensis). Plant Molecular Biology, 100, 19-32.

Hyun Y, Richter R, Coupland G (2017) Competence to flower: Age-controlled sensitivity to environmental cues. Plant Physiology, 173, 36-46.

Hyun Y, Richter R, Vincent C, Martinez-Gallegos R, Porri A, Coupland G (2016) Multi-layered regulation of SPL15 and cooperation with SOC1 integrate endogenous flowering pathways at the Arabidopsis shoot meristem. Developmental Cell, 37, 254-266.

Imaizumi T, Schultz TF, Harmon FG, Ho LA, Kay SA (2005) FKF1 F-box protein mediates cyclic degradation of a repressor of CONSTANS in Arabidopsis. Science, 309, 293-297.

Ito S, Song $\mathrm{YH}$, Josephson-Day AR, Miller RJ, Breton G, Olmstead RG, Imaizumi $\mathrm{T}$ (2012) FLOWERING BHLH transcriptional activators control expression of the photoperiodic flowering regulator CONSTANS in Arabidopsis. Proceedings of the National Academy of Sciences, USA, 109, 3582-3587.

Itoh H, Nonoue Y, Yano M, Izawa T (2010) A pair of floral regulators sets critical day length for $\mathrm{Hd} 3 \mathrm{a}$ florigen expression in rice. Nature Genetics, 42, 635-638.

Jacobsen SE, Olszewski NE, Meyerowitz EM (1998) SPINDLY's role in the gibberellin response pathway. Symposia of the Society for Experimental Biology, 51, 73-78.

Jagadish SVK, Bahuguna RN, Djanaguiraman M, Gamuyao R, Prasad PVV, Craufurd PQ (2016) Implications of high temperature and elevated $\mathrm{CO}_{2}$ on flowering time in plants. Frontiers in Plant Science, 7, 913.

Jang S, Marchal V, Panigrahi KCS, Wenkel S, Soppe W, Deng XW, Valverde F, Coupland G (2008) Arabidopsis COP1 shapes the temporal pattern of $C O$ accumulation conferring a photoperiodic flowering response. The EMBO Journal, 27, 1277-1288.

Johanson U, West J, Lister C, Michaels S, Amasino R, Dean C (2000) Molecular analysis of FRIGIDA, a major determinant of natural variation in Arabidopsis flowering time. Science, 290, 344-347.

Kim JJ, Lee JH, Kim W, Jung HS, Huijser P, Ahn JH (2012) The microRNA156-SQUAMOSA PROMOTER BINDING PROTEIN-LIKE3 module regulates ambient temperature-responsive flowering via FLOWERING LOCUS $T$ in Arabidopsis. Plant Physiology, 159, 461-478.

Kim MY, Kang YJ, Lee T, Lee SH (2013) Divergence of flowering-related genes in three legume species. The Plant Genome, 6, plantgenome2013.03.0008.

Kim S, Soltis PS, Wall K, Soltis DE (2006) Phylogeny and 
domain evolution in the APETALA2-like gene family. Molecular Biology and Evolution, 23, 107-120.

Kim W, Ahn HJ, Chiou TJ, Ahn JH (2011) The role of the miR399-PHO2 module in the regulation of flowering time in response to different ambient temperatures in Arabidopsis thaliana. Molecules and Cells, 32, 83-88.

Kinmonth-Schultz HA, Tong XR, Lee J, Song YH, Ito S, Kim $\mathrm{SH}$, Imaizumi T (2016) Cool night-time temperatures induce the expression of CONSTANS and FLOWERING LOCUS T to regulate flowering in Arabidopsis. New Phytologist, 211, 208-224.

Kinoshita A, Richter R (2020) Genetic and molecular basis of floral induction in Arabidopsis thaliana. Journal of Experimental Botany, 71, 2490-2504.

Kitamoto N, Ueno S, Takenaka A, Tsumura Y, Washitani I, Ohsawa R (2006) Effect of flowering phenology on pollen flow distance and the consequences for spatial genetic structure within a population of Primula sieboldii (Primulaceae). American Journal of Botany, 93, 226-233.

Kobayashi Y, Weigel D (2007) Move on up, it's time for change-Mobile signals controlling photoperiod-dependent flowering. Genes \& Development, 21, 2371-2384.

Kojima S, Takahashi Y, Kobayashi Y, Monna L, Sasaki T, Araki T, Yano M (2002) Hd3a, a rice ortholog of the Arabidopsis FT gene, promotes transition to flowering downstream of Hd1 under short-day conditions. Plant and Cell Physiology, 43, 1096-1105.

Komiya R, Ikegami A, Tamaki S, Yokoi S, Shimamoto K (2008) Hd3a and RFT1 are essential for flowering in rice. Development, 135, 767-774.

Kralemann LEM, Scalone R, Andersson L, Hennig L (2018) North European invasion by common ragweed is associated with early flowering and dominant changes in FT/TFL1 expression. Journal of Experimental Botany, 69, 2647-2658.

Kubota A, Ito S, Shim JS, Johnson RS, Song YH, Breton G, Goralogia GS, Kwon MS, Laboy Cintrón D, Koyama T, Ohme-Takagi M, Pruneda-Paz JL, Kay SA, MacCoss MJ, Imaizumi T (2017) TCP4-dependent induction of CONSTANS transcription requires GIGANTEA in photoperiodic flowering in Arabidopsis. PLoS Genetics, 13, e1006856.

Kumar SV, Lucyshyn D, Jaeger KE, Alós E, Alvey E, Harberd NP, Wigge PA (2012) Transcription factor PIF4 controls the thermosensory activation of flowering. Nature, 484, 242-245.

Lazaro A, Mouriz A, Piñeiro M, Jarillo JA (2015) Red light-mediated degradation of CONSTANS by the E3 ubiquitin ligase HOS1 regulates photoperiodic flowering in Arabidopsis. The Plant Cell, 27, 2437-2454.

Lee BD, Kim MR, Kang MY, Cha JY, Han SH, Nawkar GM, Sakuraba Y, Lee SY, Imaizumi T, McClung CR, Kim WY, Paek NC (2017) The F-box protein FKF1 inhibits dimerization of COP1 in the control of photoperiodic flowering. Nature Communications, 8, 2259.
Lee H, Yoo SJ, Lee JH, Kim W, Yoo SK, Fitzgerald H, Carrington JC, Ahn JH (2010) Genetic framework for flowering-time regulation by ambient temperature-responsive miRNAs in Arabidopsis. Nucleic Acids Research, 38, 3081-3093.

Leeggangers HACF, Rosilio-Brami T, Bigas-Nadal J, Rubin N, van Dijk ADJ, Gonzalez FFNC, Saadon-Shitrit S, Nijveen H, Hilhorst HWM, Immink RGH, Zaccai M (2018) Tulipa gesneriana and Lilium longiflorum PEBP genes and their putative roles in flowering time control. Plant and Cell Physiology, 59, 90-106.

Lemoine NP, Doublet D, Salminen JP, Burkepile DE, Parker JD (2017) Responses of plant phenology, growth, defense, and reproduction to interactive effects of warming and insect herbivory. Ecology, 98, 1817-1828.

Li C, Li YH, Li YF, Lu HF, Hong HL, Tian Y, Li HY, Zhao T, Zhou XW, Liu J, Zhou XN, Jackson SA, Liu B, Qiu LJ (2020) A domestication-associated gene GmPRR3b regulates the circadian clock and flowering time in soybean. Molecular Plant, 13, 745-759.

Li D, Liu C, Shen LS, Wu Y, Chen HY, Robertson M, Helliwell CA, Ito T, Meyerowitz E, Yu H (2008) A repressor complex governs the integration of flowering signals in Arabidopsis. Developmental Cell, 15, 110-120.

Li MZ, An FY, Li WY, Ma MD, Feng Y, Zhang X, Guo HW (2016) DELLA proteins interact with FLC to repress flowering transition. Journal of Integrative Plant Biology, 58, 642-655.

Li XF, Jia LY, Xu J, Deng XJ, Wang Y, Zhang W, Zhang XP, Fang Q, Zhang DM, Sun Y, Xu L (2013) FT-like NFT1 gene may play a role in flower transition induced by heat accumulation in Narcissus tazetta var. chinensis. Plant and Cell Physiology, 54, 270-281.

Li XM, Zhang DY, Liao WJ (2015) The rhythmic expression of genes controlling flowering time in southern and northern populations of invasive Ambrosia artemisiifolia. Journal of Plant Ecology, 8, 207-212.

Li ZC, Jiang DH, He YH (2018) FRIGIDA establishes a local chromosomal environment for FLOWERING LOCUS C mRNA production. Nature Plants, 4, 836-846.

Liljegren SJ, Gustafson-Brown C, Pinyopich A, Ditta GS, Yanofsky MF (1999) Interactions among APETALA1, LEAFY, and TERMINAL FLOWER1 specify meristem fate. The Plant Cell, 11, 1007-1018.

Liu FQ, Quesada V, Crevillén P, Bäurle I, Swiezewski S, Dean C (2007) The Arabidopsis RNA-binding protein FCA requires a lysine-specific demethylase 1 homolog to downregulate FLC. Molecular Cell, 28, 398-407.

Liu KD, Feng SX, Pan YL, Zhong JD, Chen Y, Yuan CC, Li HL (2016) Transcriptome analysis and identification of genes associated with floral transition and flower development in sugar apple (Annona squamosa L.). Frontiers in Plant Science, 7, 1695. 
Liu KP, Yu Y, Dong AW, Shen WH (2017) SET DOMAIN GROUP701 encodes a H3K4-methytransferase and regulates multiple key processes of rice plant development. New Phytologist, 215, 609-623.

Liu L, Liu C, Hou XL, Xi WY, Shen LS, Tao Z, Wang Y, Yu $\mathrm{H}$ (2012) FTIP1 is an essential regulator required for florigen transport. PLoS Biology, 10, e1001313.

Liu Y, Hao XY, Lu QH, Zhang WF, Zhang HJ, Wang L, Yang YJ, Xiao B, Wang XC (2020) Genome-wide identification and expression analysis of flowering-related genes reveal putative floral induction and differentiation mechanisms in tea plant (Camellia sinensis). Genomics, 112, 2318-2326.

Liu YY, Yang KZ, Wei XX, Wang XQ (2016) Revisiting the phosphatidylethanolamine-binding protein (PEBP) gene family reveals cryptic FLOWERING LOCUS T gene homologs in gymnosperms and sheds new light on functional evolution. New Phytologist, 212, 730-744.

Luo M, Tai R, Yu CW, Yang SG, Chen CY, Lin WD, Schmidt W, Wu KQ (2015) Regulation of flowering time by the histone deacetylase HDA5 in Arabidopsis. The Plant Journal, 82, 925-936.

Mathieu J, Yant LJ, Mürdter F, Küttner F, Schmid M (2009) Repression of flowering by the miR172 target SMZ. PLoS Biology, 7, e1000148.

Mátyás KK, Hegedűs G, Taller J, Farkas E, Decsi K, Kutasy B, Kálmán N, Nagy E, Kolics B, Virág E (2019) Different expression pattern of flowering pathway genes contribute to male or female organ development during floral transition in the monoecious weed Ambrosia artemisiifolia L. (Asteraceae). PeerJ, 7, e7421.

Mawphlang OIL, Kharshiing EV (2017) Photoreceptor mediated plant growth responses: Implications for photoreceptor engineering toward improved performance in crops. Frontiers in Plant Science, 8, 1181.

Méndez-Vigo B, Ausín I, Zhu WS, Mollá-Morales A, Balasubramanian S, Alonso-Blanco C (2019) Genetic interactions and molecular evolution of the duplicated genes ICARUS2 and ICARUS1 help Arabidopsis plants adapt to different ambient temperatures. The Plant Cell, 31, 1222-1237.

Méndez-Vigo B, Martínez-Zapater JM, Alonso-Blanco C (2013) The flowering repressor SVP underlies a novel Arabidopsis thaliana QTL interacting with the genetic background. PLoS Genetics, 9, e1003289.

Michaels SD, Amasino RM (2001) Loss of FLOWERING LOCUS $C$ activity eliminates the late-flowering phenotype of FRIGIDA and autonomous pathway mutations but not responsiveness to vernalization. The Plant Cell, 13, 935-941.

Michaels SD, Ditta G, Gustafson-Brown C, Pelaz S, Yanofsky M, Amasino RM (2003) AGL24 acts as a promoter of flowering in Arabidopsis and is positively regulated by vernalization. The Plant Journal, 33, 867-874.

Mitchum MG, Yamaguchi S, Hanada A, Kuwahara A, Yoshi- oka Y, Kato T, Tabata S, Kamiya Y, Sun TP (2006) Distinct and overlapping roles of two gibberellin 3-oxidases in Arabidopsis development. The Plant Journal, 45, 804-818.

Moon J, Suh SS, Lee H, Choi KR, Hong CB, Paek NC, Kim SG, Lee I (2003) The SOC1 MADS-box gene integrates vernalization and gibberellin signals for flowering in Arabidopsis. The Plant Journal, 35, 613-623.

Mulekar JJ, Huq E (2015) Arabidopsis casein kinase 2 a4 subunit regulates various developmental pathways in a functionally overlapping manner. Plant Science, 236, 295-303.

Mutasa-Göttgens E, Hedden P (2009) Gibberellin as a factor in floral regulatory networks. Journal of Experimental Botany, 60, 1979-1989.

Nie SS, Li C, Xu L, Wang Y, Huang DQ, Muleke EM, Sun XC, Xie Y, Liu LW (2016) De novo transcriptome analysis in radish (Raphanus sativus L.) and identification of critical genes involved in bolting and flowering. BMC Genomics, 17, 389.

Niu LF, Lu FL, Pei YX, Liu CY, Cao XF (2007) Regulation of flowering time by the protein arginine methyltransferase AtPRMT10. EMBO Reports, 8, 1190-1195.

Niu XM, Xu YC, Li ZW, Bian YT, Hou XH, Chen JF, Zou YP, Jiang J, Wu Q, Ge S, Balasubramanian S, Guo YL (2019) Transposable elements drive rapid phenotypic variation in Capsella rubella. Proceedings of the National Academy of Sciences, USA, 116, 6908-6913.

Oda A, Higuchi Y, Hisamatsu T (2020) Constitutive expression of CsGI alters critical night length for flowering by changing the photo-sensitive phase of anti-florigen induction in Chrysanthemum. Plant Science, 293, 110417.

Perrella G, Vellutini E, Zioutopoulou A, Patitaki E, Headland LR, Kaiserli E (2020) Let it bloom: Cross-talk between light and flowering signaling in Arabidopsis. Physiologia Plantarum, 169, 301-311.

Pin PA, Benlloch R, Bonnet D, Wremerth-Weich E, Kraft T, Gielen JJL, Nilsson O (2010) An antagonistic pair of FT homologs mediates the control of flowering time in sugar beet. Science, 330, 1397-1400.

Pin PA, Zhang WY, Vogt SH, Dally N, Büttner B, Schulze-Buxloh G, Jelly NS, Chia TYP, Mutasa-Göttgens ES, Dohm JC, Himmelbauer H, Weisshaar B, Kraus J, Gielen JJL, Lommel M, Weyens G, Wahl B, Schechert A, Müller AE (2012) The role of a pseudo-response regulator gene in life cycle adaptation and domestication of beet. Current Biology, 22, 1095-1101.

Porri A, Torti S, Romera-Branchat M, Coupland G (2012) Spatially distinct regulatory roles for gibberellins in the promotion of flowering of Arabidopsis under long photoperiods. Development, 139, 2198-2209.

Posé D, Verhage L, Ott F, Yant L, Mathieu J, Angenent GC, Immink RGH, Schmid M (2013) Temperature-dependent regulation of flowering by antagonistic FLM variants. Nature, 503, 414-417. 
Putterill J, Laurie R, MacKnight R (2004) It's time to flower: The genetic control of flowering time. BioEssays, 26, 363-373.

Reeves PA, He YH, Schmitz RJ, Amasino RM, Panella LW, Richards CM (2007) Evolutionary conservation of the FLOWERING LOCUS C-mediated vernalization response: Evidence from the sugar beet (Beta vulgaris). Genetics, 176, 295-307.

Ripoll JJ, Rodríguez-Cazorla E, González-Reig S, Andújar A, Alonso-Cantabrana H, Perez-Amador MA, Carbonell J, Martínez-Laborda A, Vera A (2009) Antagonistic interactions between Arabidopsis K-homology domain genes uncover PEPPER as a positive regulator of the central floral repressor FLOWERING LOCUS C. Developmental Biology, 333, 251-262.

Rosloski SM, Jali SS, Balasubramanian S, Weigel D, Grbic V (2010) Natural diversity in flowering responses of Arabidopsis thaliana caused by variation in a tandem gene array. Genetics, 186, 263-276.

Ruelens P, de Maagd RA, Proost S, Theißen G, Geuten K, Kaufmann K (2013) FLOWERING LOCUS C in monocots and the tandem origin of angiosperm-specific MADS-box genes. Nature Communications, 4, 2280.

Sanchez SE, Rugnone ML, Kay SA (2020) Light perception: A matter of time. Molecular Plant, 13, 363-385.

Sasani S, Hemming MN, Oliver SN, Greenup A, Tavakkol-Afshari R, Mahfoozi S, Poustini K, Sharifi HR, Dennis ES, Peacock WJ, Trevaskis B (2009) The influence of vernalization and daylength on expression of flowering-time genes in the shoot apex and leaves of barley (Hordeum vulgare). Journal of Experimental Botany, 60, 2169-2178.

Sawa M, Kay SA (2011) GIGANTEA directly activates Flowering Locus $T$ in Arabidopsis thaliana. Proceedings of the National Academy of Sciences, USA, 108, 11698-11703

Sawa M, Nusinow DA, Kay SA, Imaizumi T (2007) FKF1 and GIGANTEA complex formation is required for day-length measurement in Arabidopsis. Science, 318, 261-265.

Schiessl SV, Huettel B, Kuehn D, Reinhardt R, Snowdon RJ (2017) Flowering time gene variation in Brassica species shows evolutionary principles. Frontiers in Plant Science, 8, 1742.

Shaw LM, Li CX, Woods DP, Alvarez MA, Lin HQ, Lau MY, Chen A, Dubcovsky J (2020) Epistatic interactions between PHOTOPERIOD1, CONSTANS1 and CONSTANS2 modulate the photoperiodic response in wheat. PLoS Genetics, 16, e1008812.

Sheldon CC, Rouse DT, Finnegan EJ, Peacock WJ, Dennis ES (2000) The molecular basis of vernalization: The central role of FLOWERING LOCUS C (FLC). Proceedings of the National Academy of Sciences, USA, 97, 3753-3758.

Shibaya T, Hori K, Ogiso-Tanaka E, Yamanouchi U, Shu K, Kitazawa N, Shomura A, Ando T, Ebana K, Wu JZ, Yamazaki T, Yano M (2016) Hd18, encoding histone acetylase related to Arabidopsis FLOWERING LOCUS D, is involved in the control of flowering time in rice. Plant and Cell Physiology, 57, 1828-1838.

Shim JS, Jang G (2020) Environmental signal-dependent regulation of flowering time in rice. International Journal of Molecular Sciences, 21, 6155.

Shim JS, Kubota A, Imaizumi T (2017) Circadian clock and photoperiodic flowering in Arabidopsis: CONSTANS is a hub for signal integration. Plant Physiology, 173, 5-15.

Shindo C, Aranzana MJ, Lister C, Baxter C, Nicholls C, Nordborg M, Dean C (2005) Role of FRIGIDA and FLOWERING LOCUS C in determining variation in flowering time of Arabidopsis. Plant Physiology, 138, 1163-1173.

Simpson GG (2004) The autonomous pathway: Epigenetic and post-transcriptional gene regulation in the control of Arabidopsis flowering time. Current Opinion in Plant Biology, 7, 570-574.

Simpson GG, Dean C (2002) Arabidopsis, the Rosetta stone of flowering time? Science, 296, 285-289.

Song YH, Estrada DA, Johnson RS, Kim SK, Lee SY, MacCoss MJ, Imaizumi T (2014) Distinct roles of FKF1, GIGANTEA, and ZEITLUPE proteins in the regulation of CONSTANS stability in Arabidopsis photoperiodic flowering. Proceedings of the National Academy of Sciences, USA, 111, 17672-17677.

Song YH, Ito S, Imaizumi T (2013) Flowering time regulation: Photoperiod- and temperature-sensing in leaves. Trends in Plant Science, 18, 575-583.

Spanudakis E, Jackson S (2014) The role of microRNAs in the control of flowering time. Journal of Experimental Botany, 65, 365-380.

Srikanth A, Schmid M (2011) Regulation of flowering time: All roads lead to Rome. Cellular and Molecular Life Sciences, 68, 2013-2037.

Steffen A, Elgner M, Staiger D (2019) Regulation of flowering time by the RNA-binding proteins AtGRP7 and AtGRP8. Plant and Cell Physiology, 60, 2040-2050.

Sugano S, Andronis C, Ong MS, Green RM, Tobin EM (1999) The protein kinase CK2 is involved in regulation of circadian rhythms in Arabidopsis. Proceedings of the National Academy of Sciences, USA, 96, 12362-12366.

Sun H, Zhang WP, Wu YZ, Gao LF, Cui F, Zhao CH, Guo ZA, Jia JZ (2020) The circadian clock gene, TaPRR1, is associated with yield-related traits in wheat (Triticum aestivum L.). Frontiers in Plant Science, 11, 285.

Sun TP (2010) Gibberellin-GID1-DELLA: A pivotal regulatory module for plant growth and development. Plant Physiology, 154, 567-570.

Sung S, Amasino RM (2004) Vernalization in Arabidopsis thaliana is mediated by the PHD finger protein VIN3. Nature, 427, 159-164.

Swiezewski S, Liu FQ, Magusin A, Dean C (2009) Cold-induced silencing by long antisense transcripts of an 
Arabidopsis polycomb target. Nature, 462, 799-802.

Takada S, Goto K (2003) TERMINAL FLOWER2, an Arabidopsis homolog of HETEROCHROMATIN PROTEIN1, counteracts the activation of FLOWERING LOCUS $T$ by CONSTANS in the vascular tissues of leaves to regulate flowering time. The Plant Cell, 15, 2856-2865.

Tamaki S, Tsuji H, Matsumoto A, Fujita A, Shimatani Z, Terada R, Sakamoto T, Kurata T, Shimamoto K (2015) FT-like proteins induce transposon silencing in the shoot apex during floral induction in rice. Proceedings of the National Academy of Sciences, USA, 112, E901-E910.

Turner A, Beales J, Faure S, Dunford RP, Laurie DA (2005) The pseudo-response regulator $\mathrm{Ppd}-\mathrm{H} 1$ provides adaptation to photoperiod in barley. Science, 310, 1031-1034.

Valverde F, Mouradov A, Soppe W, Ravenscroft D, Samach A, Coupland G (2004) Photoreceptor regulation of CONSTANS protein in photoperiodic flowering. Science, 303, 1003-1006.

Verhage L, Angenent GC, Immink RGH (2014) Research on floral timing by ambient temperature comes into blossom. Trends in Plant Science, 19, 583-591.

Vermeulen PJ (2015) On selection for flowering time plasticity in response to density. New Phytologist, 205, 429-439.

Wang FF, Nan HY, Chen LY, Fang C, Zhang HY, Su T, Li SC, Cheng Q, Dong LD, Liu BH, Kong FJ, Lu SJ (2019) A new dominant locus, E11, controls early flowering time and maturity in soybean. Molecular Breeding, 39, 70.

Wang HP, Pan JJ, Li Y, Lou DJ, Hu YR, Yu DQ (2016) The DELLA-CONSTANS transcription factor cascade integrates gibberellic acid and photoperiod signaling to regulate flowering. Plant Physiology, 172, 479-488.

Wang LW, Sun S, Wu TT, Liu LP, Sun XG, Cai YP, Li JC, Jia HC, Yuan S, Chen L, Jiang BJ, Wu CX, Hou WS, Han TF (2020) Natural variation and CRISPR/Cas9-mediated mutation in GmPRR37 affect photoperiodic flowering and contribute to regional adaptation of soybean. Plant Biotechnology Journal, 18, 1869-1881.

Wang P, Gong R, Yang Y, Yu SB (2019) Ghd8 controls rice photoperiod sensitivity by forming a complex that interacts with Ghd7. BMC Plant Biology, 19, 462.

Wang SL, Gao J, Xue JQ, Xue YQ, Li DD, Guan YR, Zhang XX (2019) De novo sequencing of tree peony (Paeonia suffruticosa) transcriptome to identify critical genes involved in flowering and floral organ development. BMC Genomics, 20, 572.

Wang YY, Xiong F, Ren QP, Wang XL (2020) Regulation of flowering transition by alternative splicing: The role of the U2 auxiliary factor. Journal of Experimental Botany, 71, 751-758.

Wei JH, Choi H, Jin P, Wu YF, Yoon J, Lee YS, Quan TY, An G (2016) GL2-type homeobox gene Roc4 in rice promotes flowering time preferentially under long days by repressing Ghd7. Plant Science, 252, 133-143.
Weigel D (2012) Natural variation in Arabidopsis: From molecular genetics to ecological genomics. Plant Physiology, 158, 2-22.

Xia W, Liu R, Zhang J, Mason AS, Li ZY, Gong SF, Zhong YZ, Dou YJ, Sun XW, Fan HK, Xiao Y (2020) Alternative splicing of flowering time gene $F T$ is associated with halving of time to flowering in coconut. Scientific Reports, 10, 11640.

Xing DH, Zhao HW, Xu RQ, Li QQ (2008) Arabidopsis PCFS4, a homologue of yeast polyadenylation factor $P c f 11$, regulates FCA alternative processing and promotes flowering time. The Plant Journal, 54, 899-910.

Xu F, Li T, Xu PB, Li L, Du SS, Lian HL, Yang HQ (2016) DELLA proteins physically interact with CONSTANS to regulate flowering under long days in Arabidopsis. FEBS Letters, 590, 541-549.

Xu ML, Hu TQ, Zhao JF, Park MY, Earley KW, Wu G, Yang L, Poethig RS (2016) Developmental functions of miR156-regulated SQUAMOSA PROMOTER BINDING PROTEIN-LIKE (SPL) genes in Arabidopsis thaliana. PLoS Genetics, 12, e1006263.

Yadav A, Jayaswal PK, Venkat Raman K, Singh B, Singh NK, Usha K (2020) Transcriptome analysis of flowering genes in mango (Mangifera indica L.) in relation to floral malformation. Journal of Plant Biochemistry and Biotechnology, 29, 193-212.

Yamaguchi A, Abe M (2012) Regulation of reproductive development by non-coding RNA in Arabidopsis: To flower or not to flower. Journal of Plant Research, 125, 693-704.

Yan L, Fu D, Li C, Blechl A, Tranquilli G, Bonafede M, Sanchez A, Valarik M, Yasuda S, Dubcovsky J (2006) The wheat and barley vernalization gene VRN3 is an orthologue of FT. Proceedings of the National Academy of Sciences, USA, 103, 19581-19586.

Yan L, Loukoianov A, Tranquilli G, Helguera M, Fahima T, Dubcovsky J (2003) Positional cloning of the wheat vernalization gene VRN1. Proceedings of the National Academy of Sciences, USA, 100, 6263-6268.

Yan LL, Loukoianov A, Blechl A, Tranquilli G, Ramakrishna W, SanMiguel P, Bennetzen JL, Echenique V, Dubcovsky J (2004) The wheat VRN2 gene is a flowering repressor down-regulated by vernalization. Science, 303, 1640-1644.

Yan YY, Shen LS, Chen Y, Bao SJ, Thong ZH, Yu H (2014) A MYB-domain protein EFM mediates flowering responses to environmental cues in Arabidopsis. Developmental Cell, 30, 437-448.

Yang FX, Zhu GF, Wei YL, Gao J, Liang G, Peng LY, Lu CQ, Jin JP (2019) Low-temperature-induced changes in the transcriptome reveal a major role of CgSVP genes in regulating flowering of Cymbidium goeringii. BMC Genomics, 20, 53.

Yang L, Wang HN, Hou XH, Zou YP, Han TS, Niu XM, Zhang J, Zhao Z, Todesco M, Balasubramanian S, Guo YL (2018) Parallel evolution of common allelic variants confers 
flowering diversity in Capsella rubella. The Plant Cell, 30, 1322-1336.

Yano K, Aya K, Hirano K, Ordonio RL, Ueguchi-Tanaka M, Matsuoka M (2015) Comprehensive gene expression analysis of rice aleurone cells: Probing the existence of an alternative gibberellin receptor. Plant Physiology, 167, 531-544.

Yano M, Katayose Y, Ashikari M, Yamanouchi U, Monna L, Fuse T, Baba T, Yamamoto K, Umehara Y, Nagamura Y, Sasaki T (2000) Hd1, a major photoperiod sensitivity quantitative trait locus in rice, is closely related to the Arabidopsis flowering time gene CONSTANS. The Plant Cell, 12, 2473-2484.

Yanovsky MJ, Kay SA (2001) Signaling networks in the plant circadian system. Current Opinion in Plant Biology, 4, 429-435.

Yi H, Li XN, Lee SH, Nou IS, Lim YP, Hur Y (2017) Natural variation in CIRCADIAN CLOCK ASSOCIATED 1 is associated with flowering time in Brassica rapa. Genome, 60, 402-413.

Yun H, Hyun Y, Kang MJ, Noh YS, Noh B, Choi Y (2011) Identification of regulators required for the reactivation of FLOWERING LOCUS C during Arabidopsis reproduction. Planta, 234, 1237-1250.

Zentella R, Sui N, Barnhill B, Hsieh WP, Hu JH, Shabanowitz J, Boyce M, Olszewski NE, Zhou P, Hunt DF, Sun TP (2017) The Arabidopsis O-fucosyltransferase SPINDLY activates nuclear growth repressor DELLA. Nature Chemical Biology, 13, 479-485.

Zhang L, Jiang YY, Zhu YM, Su WB, Long T, Huang TQ, Peng JR, Yu H, Lin SQ, Gao YS (2019) Functional characteriza- tion of GI and CO homologs from Eriobotrya deflexa Nakai forma koshunensis. Plant Cell Reports, 38, 533-543.

Zhang SW, Gottschalk C, Nocker S (2019) Genetic mechanisms in the repression of flowering by gibberellins in apple (Malus $\times$ domestica Borkh.). BMC Genomics, 20, 747.

Zhao ML, Ni J, Chen MS, Xu ZF (2019) Ectopic expression of Jatropha curcas TREHALOSE-6-PHOSPHATE PHOSPHATASE $J$ causes late-flowering and heterostylous phenotypes in Arabidopsis but not in Jatropha. International Journal of Molecular Sciences, 20, 2165.

Zhong XH, Du JM, Hale CJ, Gallego-Bartolome J, Feng SH, Vashisht AA, Chory J, Wohlschlegel JA, Patel DJ, Jacobsen SE (2014) Molecular mechanism of action of plant DRM de novo DNA methyltransferases. Cell, 157, 1050-1060.

Zhu QH, Helliwell CA (2011) Regulation of flowering time and floral patterning by miR172. Journal of Experimental Botany, 62, 487-495.

Zhu Y, Liu L, Shen LS, Yu H (2016) NaKR1 regulates long-distance movement of FLOWERING LOCUS T in Arabidopsis. Nature Plants, 2, 16075.

Zicola J, Liu LY, Tänzler P, Turck F (2019) Targeted DNA methylation represses two enhancers of FLOWERING LOCUS T in Arabidopsis thaliana. Nature Plants, 5, 300-307.

Zuo ZC, Liu HT, Liu B, Liu XM, Lin CT (2011) Blue light-dependent interaction of $C R Y 2$ with SPA1 regulates COP1 activity and floral initiation in Arabidopsis. Current Biology, 21, 841-847.

(责任编委：陈进明 责任编辑：时意专) 